\title{
Take it or Leave it: Take-up, Optimal Transfer Programs, and Monitoring
}

\author{
Laurence Jacquet
}

\section{CESIFO WORKING PAPER NO. 3018}

CATEGORY 1: PUBliC FinANCE

APRIL 2010

\footnotetext{
An electronic version of the paper may be downloaded

- from the SSRN website: www.SSRN.com

- from the RePEc website: - from the CESifo website: 


\title{
Take it or Leave it: Take-up, Optimal Transfer Programs, and Monitoring
}

\begin{abstract}
This paper studies the optimal income redistribution and optimal monitoring when disability benefits are intended for disabled people but when some able agents with high distaste for work mimic them (type II errors). Labor supply responses are at the extensive margin and endogenous take-up costs may burden disabled recipients (because of either a reputational externality caused by cheaters or a snowball effect). Under paternalistic utilitarian preferences that do not compensate for distaste for work, inactive disabled recipients should obtain strictly lower consumption than disabled workers. The cost of monitoring supports adoption of an Earned Income Tax Credit. However, and surprisingly, with or without take-up costs, even if perfect monitoring is costless, it proves optimal to have type II errors. These results are robust to a utilitarian criterion. The paper provides numerical simulations calibrated on U.S. data.
\end{abstract}

JEL-Code: H21.

Keywords: optimal income taxation, tagging, take-up, extensive margin.

Laurence Jacquet
Norwegian School of Economics and Business Administration
Helleveien 30
5045 Bergen
Norway
laurence.jacquet@nh.no

March 1, 2010

In particular, I am extremely grateful to Katherine Cuff. She was particularly helpful in providing suggestions and comments at various stages of the analysis. I would also like to thank Philippe De Donder, Gregory Corcos, Gernot Doppelhofer, Timothy J. Goodspeed, Eirik Kristiansen, Laurent Simula, Erwin Ooghe, Stéphane Robin, Agnar Sandmo, Dirk Schindler, Fred Schroyen, Dirk Van de gaer and several participants at the 2009 CESifo Conference on Public Sector Economics for their advice on a previous version. The scientific responsibility is assumed by the author. 


\section{Introduction}

This paper examines the optimal redistributive structure and the optimal accuracy of monitoring when disability benefits are intended for disabled people but where some able agents who have a high distaste for work mimic them. It suggests the shape of the optimal tax-transfer system when the government operates a costly monitoring program financed by taxation of labor income.

The standard optimal taxation model assumes that individuals are distributed over some private characteristic, such as their individual productivity, the distribution of which is common knowledge. Redistribution policy is limited by incentive constraints that must be satisfied if individuals are to reveal their true productivity types (Mirrlees, 1971). These incentive compatibility constraints are relaxed and redistribution is enhanced when some characteristics correlated with low productivity (or 'tag' to use the terminology introduced by Akerlof, 1978), like disability status, are monitored for a subset of the disabled population. ${ }^{1}$

This paper differs from the existing literature by endogenizing the monitoring technology ${ }^{2}$ and all of the behavioral responses (participation to the labor market and to disability programs), which allows us to cast light on three important redistributive issues.

First, who gets the largest consumption level? The tagging literature shows that tagged disabled agents obtain a larger consumption level than untagged disabled people (e.g., Akerlof, 1978; Salanié, 2002). This result relies on the assumption that eligible people do not work whether they are tagged or untagged. However, some disabled people work, and others do not work and receive disability benefits in the real world. ${ }^{3}$ This paper models behavioral responses such as labor supply responses and take-up responses as accurately as possible and shows that the optimal ranking of consumption bundles is then reversed to give work incentives to some disabled.

Secondly, who gets the largest transfer? By definition, an Earned Income Tax Credit (EITC) provides the largest transfer to disabled or low-productivity workers. This contrasts with a Negative Income Tax (NIT), whereby nonemployed agents receive the largest transfer. As usual in the literature, let us define the ratio of social marginal utility to the marginal value of public funds as the marginal social welfare weight. Neglecting monitoring, the literature has well established that when labor supply responses are modeled along the extensive margin (i.e., the agent decides whether or not to participate in the labor force), a marginal social welfare weight lower (larger) than one on disabled workers implies a NIT (EITC) (Diamond, 1980; Saez, 2002). Contrastingly, this paper shows that, with a costly monitoring technology, a marginal social welfare weight lower than one on disabled workers does not preclude an EITC.

Third, relaxing the standard assumption that monitoring, and therefore the probability of

\footnotetext{
${ }^{1}$ In this paper, the tag (disability) is perfectly correlated with low productivity, which is the basis for redistribution. However, the tag is not perfectly observable; hence, tagging is not perfect. Contrastingly, in the seminal paper of Akerlof (1978), the tag is perfectly observable but correlated more or less perfectly with low productivity. Tagging is also not perfect.

${ }^{2}$ An exception is Boadway et al. (1999), where the accuracy of monitoring depends on the effort level of social workers. Boadway et al. (1999) characterize the optimal payment and monitoring of social workers who shirk. Shirking induces errors in screening between disabled and low-ability claimants (the latter are the able in our model). Contrastingly, the endogenous monitoring of our model depends upon the resources devoted to it and there is no agency problem involved in the tagging process. We also relax Boadway et al.'s assumption that government policy is designed such that all low-ability and disabled people apply for welfare assistance. The other differences between our model and that of Boadway et al. (1999) will become apparent as we proceed.

${ }^{3}$ In EU countries, about $30 \%$ of people who report severe disability do not get disability benefits and work (Eurostat, 2001).
} 
errors, is taken as given, this paper shows that there should always remain some type II errors (i.e., able people who falsely claim to be disabled and receive disability benefits). When the marginal cost of monitoring is very high, no monitoring (hence a type II error probability of one) is optimal. More surprising, even when monitoring is perfect and costless, it is optimal that some type II errors prevail. Since labor supply is restricted to be binary, the direct truthful mechanism that implements the optimal allocation is never fully revealing. Therefore, to reach the ideal full information allocation, the tax authority needs to not only observe the correct health status of claimants by its monitoring, but must also observe their precise disutility if they worked. Since perfect monitoring provides correct information on the health status of claimants but not on their disutility from work, having some people who commit fraud is optimal, under asymmetric information.

In this paper, optimal tax formulas are derived to provide a clear understanding of the key economic effects underlying them. This allows better analysis of the new effects that monitoring and take-up imply for standard formulas. To ease the comparison with the existing literature, these formulas are presented as functions of the behavioral elasticities.

Non-take-up may exist because of the costs of learning about and applying for the program or because of stigma costs (e.g., Sen, 1995; Currie, 2006). This paper emphasizes the endogenous stigma à la Besley and Coate (1992) as an explanation of the non-take-up phenomenon. Given the imperfect observability of disability, ${ }^{4}$ there are recipients whose decision to claim benefits can be directly attributed to laziness and not to disability. When one is truly disabled, being considered as an undeserving (i.e., lazy) recipient is demeaning and stigmatizing. This stigma increases with the number of cheaters. Although no empirical papers have studied this endogenous stigma, anecdotal evidence about people who cheat in welfare programs and then create doubts or social resentment against their peers seems persistent enough to open the path to more investigation. To the best of our knowledge, the endogenous stigma à la Besley and Coate has never been studied in the optimal income tax and tagging literature. Our optimal tax formula then includes all effects that arise from the stigma externality. Moreover, this paper also studies the robustness of the optimal tax formula to an alternative take-up cost function. Importantly, all of our results are also valid without any take-up cost.

The analysis is realized under a normative criterion corrected for features that individuals are responsible for (Bossert et al., 1999; Schokkaert et al., 2004). According to this paternalistic approach, income should not be transferred as compensation for distaste for work because individuals are responsible for their own taste for work. Moreover, disabled workers, contrary to the lazy ones, ought to be compensated for their handicap. The validity of our main results is examined and confirmed under a utilitarian criterion.

We proceed in the following section by setting up the basic model. Assuming the paternalistic criterion, Sections 3 and 4 derive the optimal tax-transfer and monitoring programs under full information and asymmetric information, respectively. Section 5 studies the robustness of the results under a utilitarian criterion. Section 6 presents some numerical results.

\footnotetext{
${ }^{4}$ In 2005 , about $80 \%$ of disability recipients suffer from mental disorders and musculoskeletal diseases (e.g., back pain) (Social Security Administration, 2006). Generally, most of these disabilities are neither easily observed nor perfectly monitored, even with a deep medical examination (Campioleti, 2002). Therefore, disability transfer systems are always imperfect. Benitez-Silva et al. (2004b) estimate that approximately $20 \%$ of applicants who are ultimately awarded benefits are not disabled.
} 


\section{The model}

\subsection{Individual's behavior}

Agents are either able or disabled. Productivities take two values, $w_{H}>w_{L}>0$, which correspond with the gross wages in two types of jobs (low and high skilled). $N_{d}$ is the proportion of disabled people in the population. Their productivity is $w_{L} . N_{a} \equiv 1-N_{d}$ is the proportion of able people in the population whose productivity is $w_{H}$. There is a perfect correlation between disability and lower productivity. This assumption is in the vein of the statutory definition of disabled people who are eligible for disability benefits. The applicant is considered to be disabled not just because of the existence of a medical impairment, but because the impairment drastically reduces his or her productivity and precludes any substantial and gainful work ( $\mathrm{Hu}$ et al., 2001). A disabled worker in a wheelchair who has the functional capability to engage in a substantial gainful job is not considered disabled either by the U.S. Social Security Act or in this model.

Assume that agents decide whether or not to work. This assumption seems natural since the empirical literature has shown that the extensive margin of labor responses is important, especially at the low income end (e.g., Meghir and Phillips, 2008) while most estimates of hours of work elasticities conditional on working are small (Blundell and MaCurdy, 1999). Utility is quasilinear and represented by:

$$
\begin{aligned}
& v(x)-\delta \text { if they work, } \\
& v(x)-\sigma \mathbb{I} \text { if they do not work, }
\end{aligned}
$$

where $x$ is consumption, $v(x): \mathbb{R}^{+} \rightarrow \mathbb{R}: x \rightarrow v(x)$ with $v^{\prime}>0 \geq v^{\prime \prime}$ and $\lim _{x \rightarrow \infty} v^{\prime}(x)=0, \delta$ is a parameter measuring disutility when working, $\mathbb{I}$ is an indicator function that takes the value of 1 if inactive agents take-up disability benefits and 0 otherwise, and $\sigma$ denotes the (endogenous) take-up cost.

The disutility of work $\delta$ is denoted $\delta_{d}$ for the $w_{L}$-agents and $\delta_{a}$ for the $w_{H}$-agents. $\delta_{d}$ is distributed according to the cumulative distribution function $F\left(\delta_{d}\right): \mathbb{R}^{+} \rightarrow[0,1]: \delta_{d} \rightarrow F\left(\delta_{d}\right)$ and the corresponding density function $f\left(\delta_{d}\right)$. The latter is continuous and positive over its domain. $\delta_{a}$ is distributed according to the cumulative distribution function $G\left(\delta_{a}\right): \mathbb{R}^{+} \rightarrow[0,1]: \delta_{a} \rightarrow G\left(\delta_{a}\right)$ and the corresponding (continuous and positive) density function $g\left(\delta_{a}\right) .{ }^{5}$ Individual characteristics are private information to each person while the distribution thereof is assumed to be public information.

The rest of this section defines the endogenous take-up cost $\sigma$ in the utility function. Let us already emphasize that all results of this paper are still valid when those take-up costs are neglected, i.e., $\sigma=0$, which is the standard assumption in the optimal taxation and tagging literature.

\section{Stigma and snowball take-up costs}

We now define the take-up cost $\sigma($.$) that can be stigma or the take-up cost of snowball.$

The phenomenon that disabled recipients are viewed with some suspicion and are vulnerable to accusations of laziness has largely been documented by psychologists and sociologists since Goffman

\footnotetext{
${ }^{5}$ We want to see whether an EITC or a NIT is optimal. This requires us to describe only the participation tax rates. Therefore, it is appropriate to assume a discrete support for skills, like in Saez (2002). For simplicity, we assume two productivity levels, but increasing the number of productivities would not modify our main results. Continuity of $\delta$ is assumed for simplicity.
} 
(1963). However, to the best of our knowledge, the economics literature has largely neglected that being considered as an undeserving (i.e., lazy) recipient when one truly is disabled is demeaning and stigmatizing. This motivates our focus on the reputational stigma à la Besley and Coate (1992). The undeserving (able) recipients impose a "reputational externality" (Besley and Coate, 1992) on the deserving (disabled) ones. ${ }^{6}$ When it is known that an individual is receiving disability benefits, other individuals infer that this individual is probably lazy. ${ }^{7}$ This creates the reputational stigma that reduces the recipients' utility. Stigma is an increasing function of the proportion of undeserving recipients in the economy, denoted by $\pi_{a}^{u}$. The undeserving beneficiaries are able agents who do not work, i.e., they are "voluntarily unemployed"; hence, the subscripts $a$ and $u$ are used. It seems realistic to assume that reputational stigma hurts deserving people more than the undeserving because the former face a limited choice set. The cost of being perceived as a cheater is lower for someone who does commit fraud (i.e., an able recipient) than for someone who does not (i.e., a disabled recipient). Without affecting the qualitative nature of the results but to later ease the notations and intuitions, we assume zero stigma effect for the able recipients. However, our results are still valid when able people also face positive stigma and the optimal tax formulas could easily be written with larger stigma on the cheaters than on the deserving. ${ }^{8}$

The definition of stigma of Besley and Coate (1992) is relevant if we consider a society where people who do their best abiding by the rules are respected and admired (even if they are quasiunproductive) and where people who do not comply with the rules (even in a cunning way) are despised. If we want to model a society where cheats and "old foxes" are admired, stigma should be a decreasing function of $\pi_{a}^{u}$. The take-up by undeserving people then has a snowball effect on take-up by the deserving. ${ }^{9}$

The type of take-up cost then depends on the first derivative: Stigma (snowball take-up cost) prevails when $\sigma^{\prime}\left(\pi_{a}^{u}\right)>0\left(\sigma^{\prime}\left(\pi_{a}^{u}\right)<0\right)$. The rest of the paper will mainly focus on the general form $\sigma^{\prime}\left(\pi_{a}^{u}\right)$, letting the reader choose the type of take-up cost she/he prefers.

\subsection{The government's decisions}

A feature of disability systems is that the eligibility of applicants is assessed on the basis of the disability status rather than being solely dependent on reported incomes. The process of

\footnotetext{
${ }^{6}$ Society is deemed to value certain individual characteristics, such as willingness to earn one's income from work when one is able to do so (e.g., Sen, 1995; Lindbeck et al., 1999). A social norm claiming that disabled, low-productivity people should get transfers also prevails (e.g., Wolff, 2004). Given the imperfect observability of disability, there are (lazy) able agents who do not deserve benefits but receive them.

${ }^{7}$ Anecdotal evidence about this reputational stigma effect also exists in politics or sport. For instance, during the 2006 Tour de France, when several exceptional cyclists were revealed to have taken drugs to improve their performances, the entire profession lost its credibility and all cyclists were suspected of being cheats.

${ }^{8}$ Introducing larger stigma on the able applicants than on the disabled ones implies that take-up costs are an ordeal associated with desirable screening (e.g., Nichols and Zeckhauser (1982) and Cuff (2000)).

${ }^{9}$ Rather than explaining the snowball effect with a society where cheats and old foxes are admired, alternative empirical explanations can prevail. In the vein of recent empirical studies that look at endogenous social interactions and peer effects (e.g., Aizer and Currie, 2004), it can become less embarrassing to live on transfers when more individuals do likewise (Lindbeck et al., 1999). Alternatively, the snowball effect can be explained by complexity or the rigor of the monitoring technology, see Kleven and Kopczuk (2010) for a model of transfer program complexity (however, without tax revenue and without administrative costs). Complexity is an instrument used by program administrators to increase the intensity of screening, hence to reduce errors. Higher complexity requires larger governmental expenditure per applicant, e.g., because of the increased number of tests and interviews with doctors. Larger monitoring expenditure per applicant reduces $\pi_{a}^{u}$, as it will be made explicit in Section 2.2. A reduction of $\pi_{a}^{u}$ could then be viewed as resulting from an increase in complexity, the latter inducing a higher cost to the applicant $\sigma($.$) (e.g., the time spent applying or a cognitive cost of having a lot of testing). Complexity is then allowed for in$ our model when $\sigma^{\prime}\left(\pi_{a}^{u}\right)<0$ is assumed.
} 
determining individual eligibility has been called "tagging" by Akerlof (1978). In Akerlof (1978), tagging allows perfect identification of a given subset of disabled people. In this paper, it is assumed that the accuracy of tagging is limited by the non-take-up phenomenon. Even if disabled people are aware of their eligibility, some of them might not claim disability benefits depending on the level of benefit and the associated stigma or take-up cost. Moreover, it is assumed that disability agencies are unable perfectly to detect able claimants.

Differing from the existing literature (Stern, 1982; Diamond and Sheshisnki, 1995; Parsons, 1996), the monitoring (tagging) technology is not exogenous in this model. The accuracy of monitoring depends on the per capita resources, $M$, devoted to it. The higher is $M$, the lower is the probability of type II error $\mu$ ("false positive"), i.e., the higher the precision with which an able agent claiming disability benefits is detected. This model analyzes the choice of monitoring expenditures, $(M)$, that is equivalent to choosing the level of type II errors $(\mu)$. Formally, the per capita cost of monitoring, $M(\mu)$, depends on the precision of the monitoring technology with $\partial M / \partial \mu<0, \partial^{2} M / \partial \mu^{2} \geqslant 0, \lim _{\mu \rightarrow 0} M(\mu)=+\infty$, and $M(1)=0 .{ }^{10}$

Under full information (so-called first-best), the disability agencies have no role to play, there is no monitoring and no type II error. Therefore, there is no stigma effect: $\sigma\left(\pi_{a}^{u}\right)=0$. The government implements a tax policy depending on $\delta$ and $w_{Y}(Y=L, H)$, hence it also assigns individuals to low-skilled jobs (where the gross wage is $w_{L}$ ), to high-skilled jobs (where the gross wage is $w_{H}$ ) or to inactivity (activity $u$ ). Activity assignment is captured through the functions $\ell_{L}\left(\delta_{d}\right): \mathbb{R}^{+} \rightarrow\{0,1\}: \ell_{L}\left(\delta_{d}\right)=1\left(\ell_{L}\left(\delta_{d}\right)=0\right)$ if $w_{L}$-agents with this value for $\delta_{d}$ are employed (inactive) and $\delta_{H}\left(\delta_{a}\right): \mathbb{R}^{+} \rightarrow\{0,1\}: \delta_{H}\left(\delta_{a}\right)=1\left(\delta_{H}\left(\delta_{a}\right)=0\right)$ if $w_{H}$-agents with this value for $\delta_{a}$ are employed (inactive). $w_{L}$-agents cannot get access to high-skilled jobs and, since efficiency matters, it will never be optimal that $w_{H}$-agents work in low-skilled jobs. By putting these people in high-skilled jobs instead of low-skilled jobs, they produce more and that increase can be used to rise consumption bundles. Hence, formally, the government determines four consumption functions: $x_{L}^{w}\left(\delta_{d}\right)$ for the $w_{L}$-workers, $x_{H}^{w}\left(\delta_{a}\right)$ for the $w_{H}$-workers, $x_{L}^{u}\left(\delta_{d}\right)$ for the $w_{L}$-inactive agents, and $x_{H}^{u}\left(\delta_{a}\right)$ for the $w_{H}$-inactive. All of these functions go from $\mathbb{R}^{+}$to $\mathbb{R}^{+}$.

We define the government's budget constraint as

$$
\begin{aligned}
& N_{d}\left[\int_{0}^{\infty}\left[\ell_{L}\left(\delta_{d}\right)\left(w_{L}-x_{L}^{w}\left(\delta_{d}\right)\right)-\left(1-\ell_{L}\left(\delta_{d}\right)\right) x_{L}^{u}\left(\delta_{d}\right)\right] d F\left(\delta_{d}\right)\right] \\
& \left.+N_{a}\left[\int_{0}^{\infty}\left[\ell_{H}\left(\delta_{a}\right)\left(w_{H}-x_{H}^{w}\left(\delta_{a}\right)\right)-\left(1-\ell_{H}\left(\delta_{a}\right)\right)\right) x_{H}^{u}\left(\delta_{a}\right)\right] d G\left(\delta_{a}\right)\right]=-R,
\end{aligned}
$$

where $R(\gtrless 0)$ is the exogenous revenue available to the economy.

This model highlights the effects of errors in distributing disability benefits. Therefore a clear boundary between eligible and noneligible people is needed. This suggests the following distinction between disutility of the disabled $\delta_{d}$ and the able $\delta_{a}$. We assume that $\delta_{d}$ measures disutility when working as a result of disability, i.e., the intensity of the physical or mental pain associated with work as a result of disability if relevant (Harkness, 1993; Cuff, 2000; Marchand et al., 2003). Contrastingly, $\delta_{a}$ is disutility when working as a result of distaste for work or work aversion. Following Arneson (1990) and Roemer (1998), people are held responsible for their taste for work $\delta_{a}$

\footnotetext{
${ }^{10}$ In summary, disability agencies do not observe either $\delta_{d}$ or $\delta_{a}$. They perfectly observe the disability status of $w_{L}$-agents (and hence their lower productivity). However, they tag some able as disabled, hence type II errors prevail.
} 
while $\delta_{d}$ stems from luck; hence, those people are not responsible for it. Therefore, able (disabled) people are unambiguously noneligible (eligible) for disability benefits. ${ }^{11}$

Our first social objective function uses a paternalistic view for the valuation of distaste for work. The government has a reference distaste for work equal to zero, i.e., it attaches a weight of zero to the distaste for work $\delta_{a}$. The paternalistic utilitarian objective states

$$
\begin{aligned}
& S^{P} \equiv N_{d}\left[\int_{0}^{\infty}\left[\ell\left(\delta_{d}\right)\left(v\left(x_{L}^{w}\left(\delta_{d}\right)\right)-\delta_{d}\right)+\left(1-\ell_{L}\left(\delta_{d}\right)\right) v\left(x_{L}^{u}\left(\delta_{d}\right)\right)\right] d F\left(\delta_{d}\right)\right] \\
& +N_{a}\left[\int_{0}^{\infty}\left[\ell_{H}\left(\delta_{a}\right) v\left(x_{H}^{w}\left(\delta_{a}\right)\right)+\left(1-\ell_{H}\left(\delta_{a}\right)\right) v\left(x_{H}^{u}\left(\delta_{a}\right)\right)\right] d G\left(\delta_{\alpha}\right)\right]
\end{aligned}
$$

This normative criterion is a sum (weighted by the share in the population) of utility functions corrected for the features that individuals are responsible for. Implicit in this approach is the idea that income should not be transferred as compensation for distaste for work $\left(\delta_{a}\right)$ because individuals are responsible for their own taste for work, and disabled workers contrary to the lazy ones ought to be compensated for their handicap. Schokkaert et al. (2004) and Cremer et al. (2007), for instance, consider this type of social objective function, but alternative paternalistic objectives are possible. Marchand et al. (2003) and Pestieau and Racionero (2009) consider another paternalistic approach in which the government attaches a larger weight to the labor disutility of disabled individuals. Our approach is also close to that used in behavioral economics when social planners does not use, in their objective function, individual preferences but their own preferences (O'Donoghue and Rabin, 2003; Kanbur et al., 2006). Maximization of paternalistic social preferences typically selects allocations that are not Pareto efficient.

Our second normative criterion is a standard utilitarian one, i.e.

$$
\begin{aligned}
& S^{U} \equiv N_{d}\left[\int_{0}^{\infty}\left[\ell\left(\delta_{d}\right)\left(v\left(x_{L}^{w}\left(\delta_{d}\right)\right)-\delta_{d}\right)+\left(1-\ell_{L}\left(\delta_{d}\right)\right) v\left(x_{L}^{u}\left(\delta_{d}\right)\right)\right] d F\left(\delta_{d}\right)\right] \\
& +N_{a}\left[\int_{0}^{\infty}\left[\ell_{H}\left(\delta_{a}\right)\left(v\left(x_{H}^{w}\left(\delta_{a}\right)\right)-\delta_{a}\right)+\left(1-\ell_{H}\left(\delta_{a}\right)\right)\left(v\left(x_{H}^{u}\left(\delta_{a}\right)\right)\right)\right] d G\left(\delta_{\alpha}\right)\right]
\end{aligned}
$$

The only differences with the paternalist criterion are in the terms $v\left(x_{H}^{w}\left(\delta_{a}\right)\right)$, which are substituted by $v\left(x_{H}^{w}\left(\delta_{a}\right)\right)-\delta_{a}$. It can be seen as contradictory to use both a utilitarian criterion and a costly monitoring technology. One screens people with high distaste for work, $\delta_{a}$, on the one hand, and compensates for distaste for work, $\delta_{a}$, by including $\delta_{a}$ in the utilitarian preferences, on the other hand. However, this is a standard objective in the optimal tax and tagging literature.

The results derived under utilitarian preferences will be given in Section 5 and compared to the ones obtained under the paternalistic utilitarian criterion. We use the superscripts $U$ and $P$ for the utilitarian and paternalistic criteria, respectively, and we drop these superscripts from the different variables for notational simplicity.

\section{Full information}

Proposition 1 In full information, everyone gets the same consumption $(\bar{x})$ under paternalistic utilitarian preferences, and a Negative Income Tax (NIT) is optimal. All able people work while only disabled agents with $\delta_{d} \leq v^{\prime}(\bar{x}) w_{L}$ do work.

\footnotetext{
${ }^{11}$ It is possible to follow the suggestion by Pestieau and Racionero (2009) to disentangle the disabled's parameter into two components: $\delta=\delta_{a}+\delta_{d}$ and again to hold people responsible for their taste parameter $\delta_{a}$ but not for their disability parameter $\delta_{d}$. However this complicates the model without bringing further analytical gains.
} 
A proof is given in Appendix A and the intuition is as follows. Suppose all able individuals are working. The social benefit of having the able individuals with the highest $\delta_{a}$ stop working is zero. The cost of having an able individual who stops working is $w_{H}(>0)$. Therefore, it is optimal that all able agents work. The same exercise can be done for disabled people. Suppose all disabled individuals are working. The social benefit of having a disabled agent endowed with $\delta_{d}$ to stop working is $\delta_{d} \in[0, \infty)$ and the social cost is $w_{L}(>0)$, which is constant. Therefore, there is a

threshold value $\widehat{\delta}_{d}$ such that those with $\delta_{d}>\widehat{\delta}_{d}$ do not work and those with $\delta_{d} \leq \widehat{\delta}_{d}$ do work. $\widehat{\delta}_{d}$ is such that the net loss of utility when the marginal disabled individuals are shifted from the disability assistance to the low-skilled job is equal to the gain of resources $\left(w_{L}\right)$ valued according to their common marginal utility, i.e., $\widehat{\delta}_{d}=v^{\prime}(\bar{x}) w_{L}$ with $\bar{x}$ denoting the consumption level. Consumption levels are the same for all individuals $(\bar{x})$ since the first-order conditions require identical marginal utility of consumption for all individuals with additively separable utility functions. Therefore, the transfer (or tax) toward the disabled workers, $\bar{x}-w_{L}$, is lower than the transfer toward the inactive disabled, $\bar{x}$. This is the definition of a Negative Income Tax (NIT), which is then optimal.

\section{Asymmetric Information}

Under asymmetric information, the tax authority is only able to observe income levels and thus can condition taxation only on income. However, when monitoring is introduced, disability agencies have access to more information than the tax authority. The optimization problem for the government takes place over three consumption bundles $x^{u}, x_{L}, x_{H}$ (in doing so, it also assigns people to work or inactivity $)^{12}$ and the optimal level of type II errors $\mu \in(0,1]$.

The government needs to take into account the set of incentive compatibility constraints (hereafter ICC) to prevent individuals from a given type from taking the tax-treatment designed for individuals of other types.

Since our objective functions are increasing in individuals' consumption, it will, just like in the first-best, never be optimal that able people work in low-skilled jobs. By putting these people in high-skilled jobs instead, they produce more that can be used to increase everyone's consumption in a way that respects the ICC and hence increases social objective value. Consequently, to induce high-skilled people to work in high-skilled jobs,

$$
x_{H} \geq x_{L},
$$

since the individual aversion to work $\delta_{a}$ is the same in both jobs. A formal proof is given in Appendix B. Therefore, no able individuals mimic disabled workers at the optimum. ${ }^{13}$ The remaining incentive problem consists in able individuals who mimic disabled recipients.

Recall that with a probability $\mu$, able individuals who claim disability benefits are accepted. With a probability $1-\mu$, they are caught and therefore go back to work. Having all detected able

\footnotetext{
${ }^{12}$ In the literature on optimal redistributive taxation initiated by Mirrlees (1971), nonemployment, if any, is synonymous with nonparticipation. There is no job search; hence, people who do not work make the choice of being inactive, i.e., there is no (so-called) involuntary unemployment. Similarly, there is no involuntary unemployment in this model. However, since disabled people face real physical or mental pain at work, they are eligible for disability benefits $\left(x^{u}\right)$.

${ }^{13}$ Equation (1) implies that only disabled people work in unskilled jobs at the optimum. Therefore, they are perfectly tagged as disabled. Being recognized as disabled is not a characteristic that implies stigma, contrarily.
} 
claimants who go back to work can be assumed but it can also be the result of the optimal tax program where able agents who claim disability benefits and are detected choose either to receive a welfare benefit or to go back to work. Appendix C states the proof.

We introduce the threshold value $\widetilde{\delta}_{a}$. It characterizes able agents who are indifferent between choosing either $v\left(x_{H}\right)-\delta_{a}$ or, with a probability $\mu, v\left(x^{u}\right)$ and with a probability $1-\mu, v\left(x_{H}\right)-\delta_{a}$. The $\mathrm{ICC}^{14}$ on agents of $w_{H}$-type can be written as:

$$
\begin{aligned}
& v\left(x_{H}\right)-\widetilde{\delta}_{a}=\mu v\left(x^{u}\right)+(1-\mu)\left[v\left(x_{H}\right)-\widetilde{\delta}_{a}\right] \\
& \Leftrightarrow \widetilde{\delta}_{a}=v\left(x_{H}\right)-v\left(x^{u}\right)
\end{aligned}
$$

such that a high-skilled agent with taste parameter $\delta_{a}$ prefers high-skilled employment to claiming benefits if and only if $\delta_{a} \leq \widetilde{\delta}_{a}$. Equation (2) emphasizes that the decision of able people to apply or not for disability benefits does not depend on the probability $\mu .^{15}$

Disabled agents choose between $v\left(x_{L}\right)-\delta_{d}$ and $v\left(x^{u}\right)-\sigma($.$) . Disabled agents characterized by$ $\delta_{d} \leq \widetilde{\delta}_{d}\left(\delta_{d}>\widetilde{\delta}_{d}\right)$ choose to work (to apply for disability benefits). Hence, the ICC on disabled states:

$$
\widetilde{\delta}_{d}=v\left(x_{L}\right)-v\left(x^{u}\right)-\sigma\left(\pi_{a}^{u}\left(\widetilde{\delta}_{a}, \mu\right)\right)
$$

with $\pi_{a}^{u}\left(\widetilde{\delta}_{a}, \mu\right)=N_{a} \mu\left(1-G\left(\widetilde{\delta}_{a}\right)\right)$, the share of population that is able and unduly collect disability benefits. Recall that we can consider either that $\sigma\left(\right.$.) represents stigma (hence, $\sigma^{\prime}\left(\pi_{a}^{u}\right)>0$ and $\sigma(.) \rightarrow 0$ if either $\widetilde{\delta}_{a} \rightarrow \infty$ or $\mu \rightarrow 0$ ), or that $\sigma($.$) represents snowball take-up costs (hence,$ $\sigma^{\prime}\left(\pi_{a}^{u}\right)<0$ and $\sigma($.$) reaches its minimum value if either \widetilde{\delta}_{a} \rightarrow 0$ or $\mu \rightarrow 1$ ), or there is no take-up cost and $\sigma\left(\pi_{a}^{u}\right)=0$. From (2) and the definition of $\pi_{a}^{u}$ :

$$
\frac{\partial \sigma}{\partial x^{u}}=-\frac{\partial \sigma}{\partial \pi_{a}^{u}} \frac{\partial \pi_{a}^{u}}{\partial \widetilde{\delta}_{a}} v^{\prime}\left(x^{u}\right)=\sigma^{\prime}\left(\pi_{a}^{u}\right) N_{a} \mu g\left(\widetilde{\delta}_{a}\right) v^{\prime}\left(x^{u}\right)
$$

Combining these results with (3), and totally differentiating gives:

$$
\frac{\partial \widetilde{\delta}_{d}}{\partial x^{u}}=-v^{\prime}\left(x^{u}\right)\left(1+\frac{\partial \sigma}{\partial \widetilde{\delta}_{a}}\right)
$$

Following an increase in $x^{u}$, the global effect on $\widetilde{\delta}_{d}$ can be decomposed into a positive direct effect and a negative indirect effect with stigma (or a positive indirect effect with the snowball take-up cost). The increase in the proportion of disabled people claiming assistance (or equivalently, the diminishing level of $\widetilde{\delta}_{d}$ ) is the direct effect. The indirect effect stems from the enlargement of stigma (the decrease of snowball take-up cost) that follows the fall in $\widetilde{\delta}_{a}$, which in turn leads to a decrease (increase) in the proportion of disabled recipients or, equivalently, to an increase (decrease) in $\widetilde{\delta}_{d}$.

Lemma 1 Active and inactive people in both ability groups coexist under asymmetric information (i.e., $\infty>\widetilde{\delta}_{d}>0$ and $\infty>\widetilde{\delta}_{a}>0$ ).

\footnotetext{
${ }^{14}$ It can easily be checked that the set of ICC for each agent of type $\left(w_{Y}, \delta_{y}\right)$ (with $\delta_{y} \in \mathbb{R}^{+}, Y=L, H$ and $y=d, a)$ can be rewritten as constraints (1)-(3).

${ }^{15}$ For agents whose $\delta_{a} \in\left(\widetilde{\delta}_{a}, \infty\right)$, the worst utility outcome when taking the lottery (i.e., when applying for benefits) is identical to the utility reached when not taking the lottery. Therefore, $\mu$ does not drive the decision to apply or not for benefits.
} 
Appendix D provides the proof.

From (2) and $\widetilde{\delta}_{a}>0$, we know that

$$
x_{H}>x^{u}
$$

The government budget constraint becomes

$$
\pi_{d}^{w}\left(w_{L}-x_{L}\right)-\left(\pi_{d}^{u}+\pi_{a}^{w}\right) x^{u}+\pi_{a}^{w}\left(w_{H}-x_{H}\right)-\left(\pi_{d}^{u}+\frac{\pi_{a}^{u}}{\mu}\right) M(\mu)=-R,
$$

where $\pi_{d}^{w}$ is the share of population that is disabled and works, $\pi_{d}^{u}$ is the share of population that is disabled and receives disability benefits, $\pi_{a}^{u}$ is the share of population that is able but unjustifiably collects disability benefits, $\pi_{a}^{w}$ is the proportion of the population that is able and works (it includes the refused undeserving claimants). Table 1 displays the proportion of individuals in each position. The per capita cost of monitoring $M(\mu)$ appears ex ante and for any individual who has applied for disability assistance, i.e., for the proportion $N_{d}\left(1-F\left(\widetilde{\delta}_{d}\right)\right)+N_{a}\left(1-G\left(\widetilde{\delta}_{a}\right)\right)=\pi_{d}^{u}+\pi_{a}^{u} / \mu$. Thus, the total cost of monitoring is increasing in the proportion of monitored individuals.

\begin{tabular}{|c|c|c|}
\hline & $\begin{array}{c}\text { recipients of } \\
\text { disability benefits }\end{array}$ & workers \\
\hline disabled $\left(w_{L}, \delta_{d}\right)$ & $\pi_{d}^{u}=N_{d}\left(1-F\left(\widetilde{\delta}_{d}\right)\right)$ & $\pi_{d}^{w}=N_{d} F\left(\widetilde{\delta}_{d}\right)$ \\
\hline able $\left(w_{H}, \delta_{a}\right)$ & $\pi_{a}^{u}=N_{a} \mu\left(1-G\left(\widetilde{\delta}_{a}\right)\right)$ & $\pi_{a}^{w}=N_{a}\left[G\left(\widetilde{\delta}_{a}\right)+(1-\mu)\left(1-G\left(\widetilde{\delta}_{a}\right)\right)\right]$ \\
\hline
\end{tabular}

Table 1: Distribution of individuals in the population

To simplify the optimal tax formulas, we can introduce more definitions. Let $T_{L}=w_{L}-x_{L}$, $T_{H}=w_{H}-x_{H}$, and $T^{u}=-x^{u}$, be the tax paid by disabled workers, able workers, and people on disability assistance, respectively. Hence, $-T^{u}$ is the disability benefit. Let us define the elasticity of participation of the disabled workers with respect to $x_{L}$ and the elasticity of the able workers with respect to $x_{H}$, respectively, as

$$
\begin{aligned}
\eta\left(x_{L}, \widetilde{\delta}_{d}\right) & \equiv \frac{x_{L}}{\pi_{d}^{w}} \frac{\partial \pi_{d}^{w}}{\partial x_{L}} \\
\eta\left(x_{H}, \widetilde{\delta}_{a}\right) & \equiv \frac{x_{H}}{\pi_{a}^{w}} \frac{\partial \pi_{a}^{w}}{\partial x_{H}}
\end{aligned}
$$

where $\partial \pi_{d}^{w} / \partial x_{L}=N_{d} f\left(\widetilde{\delta}_{d}\right) v^{\prime}\left(x_{L}\right)$ from (3) and where $\partial \pi_{a}^{w} / \partial x_{H}=N_{a} \mu g\left(\widetilde{\delta}_{a}\right) v^{\prime}\left(x_{H}\right)$ from (2). These elasticities measure the percentages of disabled (able) workers in low-skilled (high-skilled) jobs who decide to leave the labor force when $x_{L}\left(x_{H}\right)$ decreases by 1 percent.

Next, we define the marginal social welfare weight for working agents whose consumption is $x_{L}$ and $x_{H}$, respectively, as the ratio of the social marginal utility of consumption and the shadow price of the public funds:

$$
\begin{aligned}
& g_{L} \equiv \frac{v^{\prime}\left(x_{L}\right)}{\lambda} \\
& g_{H} \equiv \frac{v^{\prime}\left(x_{H}\right)}{\lambda}
\end{aligned}
$$

Disabled individuals are not responsible for the stigmatization (or snowball) phenomenon. One can then argue that they are not responsible for the impact of $\sigma$ on their well being. Therefore, 
there are good reasons to integrate it in the paternalistic utilitarian preferences $\widetilde{S}^{P}$,

$$
\widetilde{S}^{P} \equiv N_{d}\left[\int_{0}^{\widetilde{\delta}_{d}}\left(v\left(x_{L}\right)-\delta_{d}\right) d F\left(\delta_{d}\right)+\left(1-F\left(\widetilde{\delta}_{d}\right)\right)\left(v\left(x^{u}\right)-\sigma\left(\pi_{a}^{u}\right)\right)\right]+\pi_{a}^{w} v\left(x_{H}\right)+\pi_{a}^{u} v\left(x^{u}\right)
$$

The Lagrangian states as

$$
£^{P} \equiv \widetilde{S}^{P}+\lambda\left[\pi_{d}^{w}\left(w_{L}-x_{L}\right)-\left(\pi_{d}^{u}+\pi_{a}^{u}\right) x^{u}+\pi_{a}^{w}\left(w_{H}-x_{H}\right)-\left(\pi_{d}^{u}+\pi_{a}^{u} / \mu\right) M(\mu)+R\right]
$$

, where $\widetilde{\delta}_{a}\left(\widetilde{\delta}_{d}\right)$ is given by $(2)((3))$.

Next, observe that the average of the inverse of the private marginal utility of consumption is given by

$$
g_{A} \equiv \frac{\pi_{d}^{w}}{v^{\prime}\left(x_{L}\right)}+\frac{\pi_{d}^{u}+\pi_{a}^{u}}{v^{\prime}\left(x^{u}\right)}+\frac{\pi_{a}^{w}}{v^{\prime}\left(x_{H}\right)} .
$$

Let subscripts to the function $\widetilde{S}^{P}$ denote the partial derivative of $\widetilde{S}^{P}$ with respect to the argument in the subscript and note that the effect of a uniform increase in private utilities on $\widetilde{S}^{P}$ is given by

$$
D \equiv \frac{\widetilde{S}_{x_{L}}^{P}}{v^{\prime}\left(x_{L}\right)}+\frac{\widetilde{S}_{x_{H}}^{P}}{v^{\prime}\left(x_{H}\right)}+\frac{\widetilde{S}_{x^{u}}^{P}}{v^{\prime}\left(x^{u}\right)} .
$$

The following theorem states the solution for the second-best problem.

Proposition 2 Under asymmetric information, the optimal consumption levels and type II errors satisfy the budget constraint (5) and the following four equations:

$$
\begin{gathered}
\frac{T_{L}-T^{u}}{x_{L}}=\frac{1}{\eta\left(x_{L}, \widetilde{\delta}_{d}\right)}\left(g_{L}-1\right)+\frac{M(\mu)}{x_{L}} \\
\frac{T_{H}-T^{u}}{x_{H}}=\frac{1}{\eta\left(x_{H}, \widetilde{\delta}_{a}\right)}\left[\left(g_{H}-1\right)+\frac{\Omega\left(x_{H}, x_{L}, x^{u}, \mu\right)}{\pi_{a}^{w}}\right]+\frac{\widetilde{\delta}_{a}}{\lambda x_{H}}+\frac{M(\mu)}{\mu x_{H}}
\end{gathered}
$$

, where $\Omega\left(x_{H}, x_{L}, x^{u}, \mu\right)=\left(x_{L}-w_{L}+x^{u}+M(\mu)\right) \frac{\partial \pi_{d}^{w}}{\partial x_{H}}-\frac{\pi_{d}^{u}}{\lambda} \frac{\partial \sigma}{\partial x_{H}}$ applies to the indirect behavioral responses and indirect welfare change that arise from the endogenous take-up cost,

$$
\lambda^{-1}=g_{A} / D
$$

and

$$
(1-\mu) \frac{\partial £^{P}}{\partial \mu}=0 \text { and } \frac{\partial £^{P}}{\partial \mu} \geq 0
$$

The proof as well as a simple heuristic interpretation in the spirit of Saez (2002) is provided in Appendix E.

Substituting $M(\mu)=0$ in (12) yields the standard optimal tax schedule with extensive responses (Diamond, 1980; Saez, 2002). The financial incentive to enter the labor force, i.e., $T_{L}-T^{u}$, is inversely related to the participation elasticity $\eta\left(x_{L}, \widetilde{\delta}_{d}\right)$ in the vein of the inverse elasticity rule of Ramsey. Similarly, the financial incentive to enter the labor force increases with the marginal social welfare weight of (disabled) workers $\left(g_{L}\right) .{ }^{16}$ With costly monitoring $(M(\mu)>0)$, our formula

\footnotetext{
${ }^{16}$ From (12), an optimal replacement rate formula can also be derived, as done in Kroft (2008). This implies following Kroft's assumption of zero taxation in unskilled jobs, i.e., $x_{L}=w_{L}$, to neglect monitoring costs and to define the elasticity of participation by $\left[\left(x_{L}-x^{u}\right) / \pi_{d}^{w}\right]\left(\partial \pi_{d}^{w} / \partial x_{L}\right)$. Then it can easily be shown that $(12)$ becomes an optimal replacement rate formula as a function of the elasticity of participation.
} 
emphasizes that the financial incentive to enter the labor force also increases with the per capita cost of monitoring. Intuitively, monitoring costs make inactivity more expensive, hence financial incentives are needed to reduce inactivity. Corollary 1 will discuss the optimal tax formula (12) in more detail.

Compared with (12), the optimal formula (13) has two key changes given the stigma externality and the paternalistic criterion.

First, the term $\widetilde{\delta}_{a} /\left(\lambda x_{H}\right)$ is a result of the fact that the marginal disutility $\widetilde{\delta}_{a}$ is not included in the paternalistic criterion. This term appears since the effect of an infinitesimal change in the consumption bundle of able workers $\left(d x_{H}\right)$ induces the pivotal able agents to start working, which has a first-order effect on paternalistic evaluation of their well-being equal to $v\left(x_{H}\right)-v\left(x^{u}\right)$, which by virtue of (2) reduces to $\widetilde{\delta}_{a}$. The denominator in (13) converts this effect in terms of public funds and makes it relative to $x_{H}$. This term is sometimes called the paternalistic or first-best motive for taxation since it arises from differences between social and private preferences (Kanbur et al., 2006). It corrects the labor supply of able people to correspond more closely to social preferences. The term $\widetilde{\delta}_{a} /\left(\lambda x_{H}\right)$ increases their financial incentive to enter the labor force, i.e., $T_{H}-T^{u}$.

Second, $\Omega\left(x_{H}, x_{L}, x^{u}, \mu\right)$ includes all of the effects from the externality created by stigma or snowball take-up costs. An infinitesimal change $d x_{H}$ modifies the proportion of able recipients. This modifies $\sigma\left(\pi_{a}^{u}\left(\widetilde{\delta}_{a}, \mu\right)\right)$, which indirectly induces $\partial \pi_{d}^{w} / \partial x_{H}$ pivotal disabled recipients to change their occupational choice as a result of stigma (snowball take-up cost) effects. Using the envelope theorem and (2) and (3), $\partial \pi_{d}^{w} / \partial x_{H}>0(<0)$ if $\partial \sigma / \partial \widetilde{\delta}_{a}>0(<0)$. Each disabled recipient entering the labor force induces a revenue gain of $w_{L}-x_{L}+x^{u}+M(\mu)$, i.e., the tax paid by each new disabled worker $\left(w_{L}-x_{L}\right)$ and the benefit that stops being paid to him/her. There is also a gain in monitoring expenditures $(M(\mu))$ for the disabled who stop applying for disability benefits. Hence, the total gain is $\left(w_{L}-x_{L}+x^{u}+M(\mu)\right)\left(\partial \pi_{d}^{w} / \partial x_{H}\right) d x_{H}$. The change $d x_{H}$ also affects welfare through a change in the stigma intensity of the $\pi_{d}^{u}$ disabled recipients. This change in terms of public funds is valued $-\pi_{d}^{u}\left(\partial \sigma / \partial x_{H} / \lambda\right) d x_{H}$ by the government. Then, all of the indirect effects implied by the stigma (take-up cost) externality when $d x_{H}>0$ are denoted by $\Omega\left(x_{H}, x_{L}, x^{u}, \mu\right)$ defined in Proposition 2 .

Equation (14) is similar to Diamond and Sheshinski (1995)'s equation (6), p. 6. It yields an important redistributive principle of the optimal redistributive programs, which prevails independently of stigma effects. It is associated with an equal marginal change of the consumption of everyone in the economy. Consider a uniform increase in all private utilities of one unit. This does not change activity decisions. To accomplish this uniform increase, we need per $w_{Y}$-worker $1 / v^{\prime}\left(x_{Y}\right)$ extra units of consumption $(Y=L, H)$, and per inactive person we need $1 / v^{\prime}\left(x^{u}\right)$ extra units of consumption. Weighting this by the frequencies of these groups in the population, we find that we need an additional $g_{A}\left(x^{u}, x_{L}, x_{H}, \widetilde{\delta}_{d}, \widetilde{\delta}_{a}\right)$ units of public revenue to finance this operation. In terms of social welfare, this is worth $\lambda g_{A}\left(x^{u}, x_{L}, x_{H}, \widetilde{\delta}_{d}, \widetilde{\delta}_{a}\right)$. This has to be equal to the increase in the social objective function caused by the uniform increase in utilities, which is equal to $D$. Remarkably, under paternalistic utilitarian preferences, $D=1$ from (11). Equation (14) thus equates the inverse of the marginal cost of public funds to the ratio of the average of the inverse of the private utilities and the marginal social utility of a uniform increase in all individual utilities, the latter being equal to one under paternalism. Multiplying both sides of (14) by $\lambda$, this 
principle can be rephrased as: the average (using population proportions) value of the inverses of the marginal welfare weights is one.

Equation (15) is developed in Appendix E (see Equation (23)). In case of an interior solution $(\mu<1)$, the optimal amount of monitoring is such that the impact of a small increase in the probability of type II errors $d \mu>0$ cancels out the mechanical and behavioral effects (detailed in Appendix E) such that $\partial £ / \partial \mu=0 .{ }^{17}$ When the marginal cost of monitoring $|\partial M / \partial \mu|$ is not huge, monitoring is always optimal (i.e., $\mu<1$ ) because it reduces the number of undeserving recipients, thereby improving efficiency. It also reduces stigmatization (with $\partial \sigma / \partial \mu>0$ ). However, when $|\partial M / \partial \mu|$ is very high, $\mu=1$ prevails at the optimum. No monitoring is optimal, as whoever applies for disability benefits obtains them. From simulations, Section 6 shows when monitoring becomes suboptimal (i.e., $\mu=1$ ).

It is well known (Diamond 1980) that subsidizing low-paid workers more than inactive people (i.e., $T_{L}<T_{u}$ ) can be optimal when labor supply is modeled along the extensive margin. Using the definition of Saez (2002), an Earned Income Tax Credit (EITC) is then optimal. On the other hand, when $T_{L}>T_{u}$, a Negative Income Tax (NIT) is optimal. With labor supply modeled along the extensive margin, Saez (2002) shows that an EITC or NIT prevails depending on whether $g_{L} \geq 1$ or $g_{L}<1$. The following corollary emphasizes that the sufficient condition for an EITC is still valid with costly monitoring, but not under NIT. Costly monitoring supports the use of an EITC since it makes inactivity more expensive.

Corollary 1 With costless monitoring, an EITC or a NIT is optimal depending on $g_{L} \geq 1\left(g_{L}<\right.$ 1) (Saez, 2002). With costly monitoring, $g_{L} \geq 1$ implies an EITC, and the EITC result can also carry through with $g_{L}<1$.

Proof. From (12), $g_{L} \geq 1 \Leftrightarrow T_{L}-T^{u} \geq M(\mu)$; hence, an EITC is optimal. This result prevails with $M(\mu) \geq 0$. Moreover, from (12), $g_{L}<1 \Leftrightarrow T_{L}-T^{u}<M(\mu)$. Therefore, $M(\mu)=0$ implies that a NIT is optimal. When $M(\mu)>0$ (i.e., $\mu<1$ ), the previous inequality does not imply $T_{L}<T_{u}$ (i.e., a NIT) anymore.

At this stage of the analysis, it becomes obvious that Lemma 1, Proposition 2, and Corollary 1 may easily be extended to a more general utility function, but at the cost of more extensive notation and derivations without bringing further economic intuitions and results, so we prefer to stick to the simple quasilinear form.

Interestingly, Corollary 1 and the next proposition highlight that the government should offer particularly strong financial incentives to the disabled and not trap all of them into inactivity. This supports adoption of an EITC (Corollary 1) and, in addition, because the consumption then received by disabled workers is necessarily larger than that of those who are non-employed:

Proposition 3 Consumption of workers in low-skilled jobs is strictly larger than the disability benefit, $x_{L}>x^{u}$.

\footnotetext{
${ }^{17}$ In a model with a perfect (i.e., without any error) but costly monitoring technology, Cremer et al. (2007) show that the optimal number of monitored people is determined by the trade-off between the negative effect of monitoring on public expenditures (i.e., the mechanical loss in monitoring expenditures) and its positive effect via the welfare gain stemming from less stringent ICC. Similarly, in our model, decreasing $\mu$ implies a mechanical loss in monitoring expenditures and gains on government revenue as a result of behavioral responses. In our model, modifying monitoring also affects the stigma (snowball take-up cost). This externality modifies welfare and implies behavioral responses from disabled agents.
} 
Appendix $\mathrm{F}$ states the proof. The result $x_{L}>x^{u}$ can seem counterintuitive at first sight for two reasons. First, those who get the lowest consumption are also those who suffer from stigma. Second, our result contrasts with those of Akerlof (1978) and Salanié (2002). They show analytically that tagged disabled people obtain larger consumption than untagged ones, i.e., $x_{L}>x^{u}$. In this literature, tagging improves equity by giving higher transfers to some of the more needy. At the same time, tagging also improves efficiency by circumventing the ICC that normally limits the extent of redistribution.

The reverse ranking of consumption levels obtained in Proposition 3 can intuitively be explained by a new efficiency effect. The latter appears when the tagged population includes a proportion of disabled who are ready to work, and it is not optimal to release that proportion from work activity. It implies that disabled workers should receive higher consumption than is provided to those disabled persons who do not work, $x_{L}>x^{u}$. In standard tagging models, since the disabled are by assumption always inactive, no efficiency effect will push the consumption of untagged disabled above that of the tagged disabled. ${ }^{18}$

The next proposition points out that when perfect monitoring can be realized without any governmental spending, using it is, however, not optimal.

Proposition 4 With costless monitoring, perfect monitoring (i.e., $\mu=0$ ) is not optimal under paternalistic utilitarian preferences. This result holds with or without stigma.

Appendix G gives the proof. This quite surprising result relies on the fact that, since the labor supply is restricted to be binary, the directly truthful mechanism that implements the optimal allocations is never fully revealing (see Equations (2)-(3)). Workers fully reveal their $w_{Y}(Y=L, H)$ information but not their $\delta$ value, and they announce only that their $\delta$ is larger than $\widetilde{\delta}_{y}$ with $y=d$ $(y=a)$ for $w_{L}\left(w_{H}\right)$-workers. Moreover, inactive agents do not reveal either their exact $w_{Y}$ or their $\delta_{y}$. In this context, monitoring improves information on the inactive but full revelation never occurs. In other words, even when $\mu=0$ is feasible without any cost, an instrument is still missing to reach the first-best. To implement the first-best allocation, the tax authority would need to observe not only the health status (through perfect monitoring) but also the precise $\delta$ level.

We have emphasized that costless and perfect monitoring does not imply full information. Now, let us recall that the full information optimum is characterized by all able agents who work (Proposition 1). In the second-best, perfect monitoring allows that all able agents work (hence, stigma is zero, if any). However, even when this does not cost anything, it is always optimal to have imperfect monitoring. This can be intuitively explained as follows. In the second-best with costless and perfect monitoring $(\mu=0)$, equalizing the consumption levels such that we tend toward the first-best optimum, all disabled agents stop working and create a considerable loss of tax revenue. This sharply contrasts with the first-best allocation where the disabled with $\delta_{d}$ below some threshold do work. Using financial incentives, $x_{L}>x^{u}$, is the only way to guarantee that some disabled agents work in the second-best (since we do not observe their individual disutility). Moreover, financial incentives for able agents are also required to avoid that they all only work in low-skilled jobs. The lowest financial incentive such that they all work in high-skilled jobs is

\footnotetext{
${ }^{18}$ This result is in the vein of a "dual-NIT system' (Parsons, 1996), where some able people who get disability benefits (type II errors) also receive incentives to work.
} 
$x_{H}=x_{L}, \mu$ being equal to zero. In other words, $\mu=0$ yields $\lambda=v^{\prime}\left(x_{H}\right)=v^{\prime}\left(x_{L}\right)<v^{\prime}\left(x^{u}\right)$ (as also emphasized in the proof in Appendix G). This has a welfare cost for the disabled that implies that $\mu>0$ (hence, $v^{\prime}\left(x_{H}\right)<\lambda$ ) is preferred.

Interestingly, this result holds with stigma, with snowball take-up cost, or without either of them. Our model does not require take-up costs to show that no type II error is suboptimal.

We believe that this result may be of some use for policy recommendations. In Norway for instance, several economists and politicians have recently proposed strengthening controls in disability programs to eliminate those able people who abuse the system. In the current budgetary, demographic, and economic contexts, to cut unnecessary costs may be a good idea. However, a government that, roughly speaking, wants to help the disabled but not lazy able persons should allow some cheating, according to Proposition 4. This occurs because to reach the ideal first-best optimum requires not only perfect information on the health status of claimants (able versus disabled) but also their precise disutility of work given their handicap. Since this is not feasible, perfect monitoring would be welfare-reducing.

\section{The utilitarian criterion}

This section emphasizes that most of the results we have derived under paternalistic utilitarian preferences are still valid under the utilitarian criterion, $S^{U}$.

Proposition 5 In full information, everyone receives the same consumption $\bar{x}$ under utilitarian preferences and a NIT prevails. Disabled and able agents with $\delta_{y}>\widehat{\delta}_{y}=v^{\prime}(\bar{x}) w_{Y} \quad(y, Y)=(d, L)$ or $(a, H)$, do not work.

The proof is provided in Appendix A. Under full information, it is optimal to have able people who do not work and receive disability benefits, under utilitarian preferences. This result contrasts with the full information optimum under the paternalistic utilitarian criterion (Proposition 1).

In the second-best, because of the ICC, the utilitarian preferences become

$$
\begin{aligned}
& \widetilde{S}^{U} \equiv N_{d}\left[\int_{0}^{\widetilde{\delta}_{d}}\left(v\left(x_{L}\right)-\delta_{d}\right) d F\left(\delta_{d}\right)+\left(1-F\left(\widetilde{\delta}_{d}\right)\right)\left(v\left(x^{u}\right)-\sigma\left(\pi_{a}^{u}\right)\right)\right] \\
& +N_{a}\left[\left(G\left(\widetilde{\delta}_{a}\right)+(1-\mu)\left(1-G\left(\widetilde{\delta}_{a}\right)\right)\right) v\left(x_{H}\right)-\int_{0}^{\widetilde{\delta}_{a}} \delta_{a} d G\left(\delta_{a}\right)\right. \\
& \left.-(1-\mu) \int_{\widetilde{\delta}_{a}}^{\infty} \delta_{a} d G\left(\delta_{a}\right)+\mu\left(1-G\left(\widetilde{\delta}_{a}\right)\right) v\left(x^{u}\right)\right]
\end{aligned}
$$

The following proposition gives the optimal second-best allocation.

Proposition 6 In asymmetric information, the utilitarian optimal consumption levels and type II errors satisfy the budget constraint (5), Equations (12), (14), and (15), and

$$
\frac{T_{H}-T^{u}}{x_{H}}=\frac{1}{\eta\left(x_{H}, \widetilde{\delta}_{a}\right)}\left[\left(g_{H}-1\right)+\frac{\Omega\left(x_{H}, x_{L}, x^{u}, \mu\right)}{\pi_{a}^{w}}\right]+\frac{M(\mu)}{\mu x_{H}}
$$

Since the proof is identical to the one in Proposition 2, it is skipped here. There is no more change in welfare (directly) due to the behavioral response of the pivotal able workers leaving the labor 
force, characterized by $\delta_{a}=\widetilde{\delta}_{a}$. Their well-being weight is now the same, in the social preferences, whether they are recipients or workers. Therefore, compared with Equation (13) in Proposition 2, the paternalistic term $\widetilde{\delta}_{a} /\left(\lambda x_{H}\right)$ does not appear in the above equation.

From Equation (12) in Proposition 6, it is straightforward to see that Corollary 1 is still valid under utilitarianism. Again, monitoring supports an EITC.

Proposition 7 Under utilitarianism, the consumption of workers in low-skilled jobs is strictly larger than the disability benefit, $x_{L}>x^{u}$.

Since the proof is identical to the one of Proposition 3, it is skipped here. The intuition is identical to the one we provided for Proposition 3.

Proposition 8 With costless monitoring, perfect monitoring (i.e., $\mu=0$ ) is not optimal under utilitarianism. This result holds with or without stigma.

The proof is identical to the one of Proposition 4 (in Appendix G). Under utilitarianism, as with the paternalistic utilitarian criterion, $\mu=0$ coexists with $x_{H}=x_{L}>x^{u}$. Moreover, perfect monitoring implies that all able never obtain disability benefits. Contrastingly, in the first-best utilitarian optimum, disabled but also able agents (with $\delta$ above some threshold values) do not work (Proposition 5). This is never reached with $\mu=0$. Hence, even if costless, $\mu=0$ is not optimal in the second-best.

\section{An illustration}

This section implements our optimal tax formulas to check when monitoring becomes suboptimal, as expected from the discussion of Equation (15) in Proposition 2.

\subsection{Calibration}

To calibrate the model, we specify a logarithmic utility function, $v(.) \equiv \ln ($.$) and a linear take-up$ cost function, $\sigma\left(\pi_{a}^{u}\right)=s \pi_{a}^{u}$ with $s \in \mathbb{R}$. There is no empirical evidence concerning the disutility of work as a result of disability or aversion to work. Therefore, $\delta_{d}$ and $\delta_{a}$ are distributed according to Gamma distributions since those distributions take a very large variety of shapes by perturbing only its $r$ parameter. ${ }^{19}$ Let $r_{\delta_{d}}, r_{\delta_{a}}$ be the parameters characterizing Gamma distributions, respectively, for $\delta_{d}$ and $\delta_{a}$. In 1998, almost $20 \%$ of people in the U.S. reported some level of disability (Stoddard et al., 1998). In 2001, almost $15 \%$ of the population of working age from EU countries reported severe and moderate disability (Eurostat, 2001). Following Benitez-Silva et al. (2004a), who show that the hypothesis that self-reported disability is an unbiased indicator that cannot be rejected,

${ }^{19}$ The density of a Gamma is given by:

$$
f(y)=\frac{1}{\Gamma(r)} \exp (-y) y^{r-1}
$$

, where $\Gamma(r)$ is a Gamma law of parameter and the latter is equal to the mean and the variance of the distribution. We have checked that our conclusions are maintained with other continuous distributions defined on the infinite support $[0,+\infty)$. 
we take $N_{d}=0.15$ as a benchmark. Here, with two levels of skills, assumptions about $w_{H}$ and $w_{L}$ cannot be based on actual earnings distributions. The base setting for the parameters is

$$
s=3, r_{\delta_{d}}=5, r_{\delta_{a}}=1, w_{L}=50, w_{H}=100 \text { and } R=0 .
$$

In all of our simulations, we consider $R$ strictly larger than $-\left[N_{d} w_{H}+N_{a} w_{L}\right]=-92.5$; otherwise, the budget constraint (5) is violated. The specification of the monitoring function is

$$
M(\mu)=m(1 / \mu-1) \quad \text { with } m>0 .
$$

The value of $m$ is given by (16), where $\mu$ and $M(\mu)$ are replaced by empirical estimates as follows. Benitez-Silva et al. (2004b) estimate that approximately $20 \%$ of applicants who are ultimately awarded benefits are not disabled; hence, $\mu=0.2$. The (average) monthly disability benefit is $\$ 786$, about the (average) labor earnings of disabled people $w_{L}$ (however, the variance is large), and the average cost of running the Social Security Administration (Disability Insurance) bureaucracy, which determines eligibility for disability benefits, is about $\$ 2000$ per application in the U.S. (Benitez-Silva et al., 2004b). The claims are typically reviewed every year. Hence, the monthly average per capita cost of monitoring is $\$ 166.7$. Therefore, $w_{L}=4.7 M$. Since $w_{L}=50, M=10.6$. $M(\mu) \in[7.5 ; 15]$ is considered to get a range of empirically relevant parameters. Substituting $\mu=0.2$ and $M \in[7.5 ; 15]$ into (16) gives an interval of plausible values for $m$, i.e., $m \in[1.8 ; 3.8]$.

Simulations were performed with Mathematica software and our programs are available upon request. Technical details of the simulations are described in Appendix H.

\subsection{Simulations}

A first exercise gives the threshold values of $m$ in (16) beyond which monitoring is suboptimal (i.e., $\mu=1$ ). With the paternalistic utilitarian criterion, monitoring is suboptimal when $m \geq$ 73. With the utilitarian criterion, monitoring is suboptimal $(\mu=1)$ when $m \geq 50.3$. Those threshold values are large relative to labor earnings in low-skilled jobs $\left(w_{L}=50\right)$ or relative to (per capita) governmental exogenous resources $(R=0)$. These thresholds also seem unrealistically high compared with the interval of empirically plausible values, $1.8 \leq m \leq 3.8$. All our unreported simulations give unrealistic high threshold values.

Simulations also allow the emphasis of another situation where monitoring is suboptimal and cannot be captured by the first-order conditions. Under the utilitarian criterion, when the exogenous resources $R$ become very high (and larger than $m$ and $w_{H}$ according to all of our simulations), monitoring becomes suboptimal. Figure 1 illustrates this with $m=2$. Under utilitarianism, monitoring becomes suboptimal when $R \geq 130.96$. At $R=130.96$, there is a discontinuity in the probability of type II errors $\mu$, which jumps up to 1 . The proportion of able workers, $\pi_{a}^{w}$, then sharply shrinks. And there is a discontinuity in $\pi_{a}^{w}$ at $R=130.96$ (see Figure 1). Intuitively, since the disutility terms $\delta_{a}$ reduces the utilitarian welfare level, it is optimal that more and more able workers stop working when $R$ increases. Under paternalistic utilitarianism, our simulations never report a threshold $R$ beyond which monitoring is suboptimal. Taking large ranges of $\left(s, R, w_{L}, w_{H}, N_{d}, m\right)$ (such that monitoring is optimal), we varied $R$ but never found any case where monitoring became suboptimal. Intuitively, able people who stop working reduce efficiency without improving equity under the paternalistic criterion. Therefore, under paternalism, the proportion of able people who 


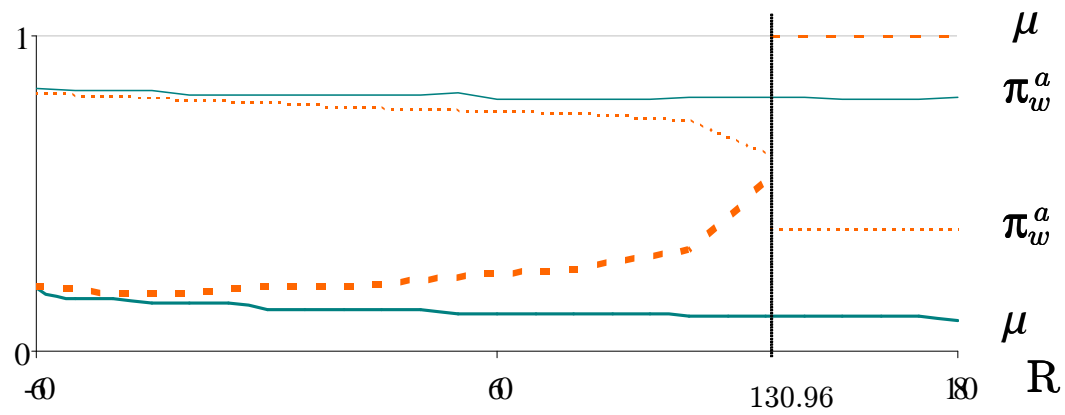

\section{Paternalistic Utilitarian}

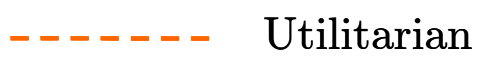

Figure 1: Optimal probability of type II error and proportion of able workers as functions of $R$.

work, $\pi_{a}^{w}$, is stable (see Figure 1 where $m=2$ ) with $R$. Financial incentives and monitoring are both used to keep $\pi_{a}^{w}$ high and stable. When governmental resources $R$ increase, Type II errors are reduced. They decrease from $20 \%$ to $10 \%$ when $R$ increases from -60 to 180 .

\section{Conclusion}

This paper assumed an economy where lazy able people may pretend to be disabled and where some disabled people may not take up disability benefits designed for them. It has been shown that modeling the monitoring technology and the participation decisions (participation in the labor market and in disability programs) is critical to designing the optimal tax schedule. Formulas for optimal taxation and optimal monitoring accuracy have been provided under paternalistic utilitarian and utilitarian preferences. It has been shown that expensive monitoring supports the use of an Earned Income Tax Credit. We have also discussed how introducing some endogenous take-up cost (as in Besley and Coate, 1992) modifies the optimal tax formula.

This paper has also shown that when monitoring is costless, perfect monitoring is not optimal. In other words, some cheating is always optimal. Our simulations have shown the quantitative sensitivity of the optimal level of type II errors.

\section{A Proofs of Propositions 1 and 5}

The Lagrangian states as

$$
\begin{aligned}
& £=S^{X}+\lambda\left\{N_{d}\left[\int_{0}^{\infty}\left[\ell\left(\delta_{d}\right)\left(w_{L}-x_{L}^{w}\left(\delta_{d}\right)\right)-\left(1-\ell\left(\delta_{d}\right)\right) x_{L}^{u}\left(\delta_{a}\right)\right] d F\left(\delta_{d}\right)\right]\right. \\
& \left.+N_{a}\left[\int_{0}^{\infty}\left[\ell\left(\delta_{a}\right)\left(w_{H}-x_{H}^{w}\left(\delta_{a}\right)\right)-\left(1-\ell\left(\delta_{a}\right)\right) x_{H}^{u}\left(\delta_{a}\right)\right] d G\left(\delta_{a}\right)\right]-R\right\}
\end{aligned}
$$

where $\lambda$ is the (nonnegative) Lagrangian multiplier associated with the budget constraint. We discuss the paternalistic utilitarian case first (i.e., $X=P$ ), and show how the properties of the 
utilitarian case $(X=U)$ follow.

For any pair $\left(\delta_{d}, \delta_{a}\right)$, the first-order conditions with respect to the four consumption functions can be written as:

$$
\begin{aligned}
& \ell\left(\delta_{d}\right)\left[v^{\prime}\left(x_{L}^{w}\left(\delta_{d}\right)\right)-\lambda\right]=0 \\
& \left(1-\ell\left(\delta_{d}\right)\right)\left[v^{\prime}\left(x_{L}^{u}\left(\delta_{d}\right)\right)-\lambda\right]=0 \\
& \ell\left(\delta_{a}\right)\left[v^{\prime}\left(x_{H}^{w}\left(\delta_{a}\right)\right)-\lambda\right]=0 \\
& \left(1-\ell\left(\delta_{a}\right)\right)\left[v^{\prime}\left(x_{H}^{u}\left(\delta_{a}\right)\right)-\lambda\right]=0
\end{aligned}
$$

Since $\ell\left(\delta_{y}\right) \quad(y=d, a)$ is equal to 1 or 0 , only two of these first-order conditions matter. For those that matter, the corresponding social marginal utilities of consumption have to be equal. For the other two, the consumption function does not matter (as nobody with this value for $\delta_{y}$ is receiving it). Therefore, since $\lambda$ is a constant, we have that the first-order conditions with respect to consumption reduce to $\forall\left(\delta_{d}, \delta_{a}\right)$ :

$$
\begin{aligned}
& v^{\prime}\left(x_{L}^{w}\left(\delta_{d}\right)\right)=v^{\prime}\left(x_{L}^{u}\left(\delta_{d}\right)\right)=v^{\prime}\left(x_{H}^{w}\left(\delta_{a}\right)\right)=v^{\prime}\left(x_{H}^{u}\left(\delta_{a}\right)\right)=\lambda \\
& \Longleftrightarrow \bar{x}=x_{L}^{w}\left(\delta_{d}\right)=x_{L}^{u}\left(\delta_{d}\right)=x_{H}^{w}\left(\delta_{a}\right)=x_{L}^{u}\left(\delta_{a}\right),
\end{aligned}
$$

From (17), the tax/transfer toward the disabled workers, $\bar{x}-w_{L}$, is lower than the transfer to the inactive disabled, $\bar{x}$. A NIT is optimal. From the budget constraint, we have

$$
\bar{x}=N_{d} w_{L} \int_{0}^{\infty} \ell\left(d_{\delta}\right) d F\left(d_{\delta}\right)+N_{a} w_{H} \int_{0}^{\infty} \ell\left(\delta_{a}\right) d G\left(\delta_{a}\right)+R
$$

$\bar{x}$ only depends on the number of disabled and the number of able agents who are employed. Consequently, the value of our objective function becomes

$$
\begin{aligned}
& v\left(N_{d} w_{L} \int_{0}^{\infty} \ell\left(\delta_{d}\right) d F\left(\delta_{d}\right)+N_{a} w_{H} \int_{0}^{\infty} \ell\left(\delta_{a}\right) d G\left(\delta_{\alpha}\right)+R\right) \\
& -N_{d} \int_{0}^{\infty} \ell\left(\delta_{d}\right) \delta_{d} d F\left(\delta_{d}\right)
\end{aligned}
$$

The value of our objective function is maximal when all able agents work: $\ell\left(\delta_{a}\right)=1 \forall \delta_{a}$. Therefore, from the budget constraint, we have $\bar{x}=N_{d} w_{L} \int_{0}^{\infty} \ell\left(d_{\delta}\right) d F\left(d_{\delta}\right)+N_{a} w_{H}+R$. Further, as $\delta_{d}$ rises from 0 to $\infty$, the function $\ell\left(\delta_{d}\right) \delta_{d}$, where $\ell\left(\delta_{d}\right)=1 \forall \delta_{d}$, goes from 0 to $\infty$. Hence, among the disabled, it will always be optimal to have those in work with the lowest $\delta_{d}$. Consequently, the function $\ell\left(\delta_{d}\right)$ will have the following shape: $\ell\left(\delta_{d}\right)=1$ for all $\delta_{d} \leq \widehat{\delta}_{d}$ and $\ell\left(\delta_{d}\right)=0$ otherwise. The critical value is determined by

$$
\begin{aligned}
& v^{\prime}(\bar{x}) N_{y} w_{Y} f\left(\widehat{\delta}_{y}\right)-N_{y} \widehat{\delta}_{y} f\left(\widehat{\delta}_{y}\right)=0 \\
& \Leftrightarrow \widehat{\delta}_{y}=v^{\prime}(\bar{x}) w_{Y}>0,
\end{aligned}
$$

with $(y, Y)=(d, L)$. Since $v^{\prime}(\bar{x})$ and $w_{L}$ are finite, $\widehat{\delta}_{d}<\infty$. It implies that it is optimal for some disabled individuals not to work.

Under utilitarian preferences $S^{U}$, it is easy to see that the same first-order conditions as under $S^{P}$ are obtained, and so the solution is given by (17). Again, we drop the superscript $X=U$ to 
ease the notations. From the budget constraint, we then have (18). Substituting (18) in $S^{U}$ gives the value of utilitarian welfare as a function of the $\ell\left(\delta_{d}\right)$ and $\ell\left(\delta_{a}\right)$ functions:

$$
\begin{aligned}
& v\left(N_{d} w_{L} \int_{0}^{\infty} \ell\left(\delta_{d}\right) d F\left(\delta_{d}\right)+N_{a} w_{H} \int_{0}^{\infty} \ell\left(\delta_{a}\right) d G\left(\delta_{\alpha}\right)+R\right) \\
& -N_{d} \int_{0}^{\infty} \ell\left(\delta_{d}\right) \delta_{d} d F\left(\delta_{d}\right)-N_{a} \int_{0}^{\infty} \ell\left(\delta_{a}\right) \delta_{a} d F\left(\delta_{a}\right) .
\end{aligned}
$$

Keeping the number of employed of both types fixed, it is only through the terms on the last line that the shape of the $\ell\left(\delta_{d}\right)$ and $\ell\left(\delta_{a}\right)$ functions matter under utilitarianism. Hence, as $\delta_{k}$ $(k=d, a)$ rises from 0 to $\infty$, the function $\ell\left(\delta_{k}\right) \delta_{k}$, where $\ell\left(\delta_{k}\right)=1 \forall \delta_{k}$, goes from 0 to $\infty$. Then it is always optimal to have those in work with the lowest $\delta_{k}(k=d, a)$. Therefore, the functions $\ell\left(\delta_{d}\right)$ and $\ell\left(\delta_{a}\right)$ have the following shape: $\ell\left(\delta_{d}\right)=1$ for all $\delta_{d} \leq \widehat{\delta}_{d}$, otherwise zero and $\ell\left(\delta_{a}\right)=1$ for all $\delta_{a} \leq \widehat{\delta}_{a}$, otherwise zero. Both critical values satisfy (19) with $(y, Y)=(d, L)$ and $(a, H)$, respectively. Differing from the optimum under the paternalistic criterion, since $v^{\prime}(\bar{x})$ and $w_{H}$ are finite, we now have $\widehat{\delta}_{a}<\infty$, i.e., there are able agents who do not work and receive benefits. From $w_{H}>w_{L}$ and (19), $\widehat{\delta}_{a}>\widehat{\delta}_{d}$ as under paternalism.

\section{B Proof of Equation (1)}

By contrast, suppose $x_{H}<x_{L}$. All able individuals who work choose to produce $w_{L}$ units and receive net income $x_{L}$. From (2) and (3), nobody gets $x_{H}$ as a consumption bundle. Then, keeping $x_{L}$ fixed, we can assume $d x_{H}>0$ such that $x_{H}+d x_{H}=x_{L}$. Now, able people who work produce $w_{H}$ units and get $x_{H}$ as a consumption bundle. Increasing the level of $x_{H}$ up to $x_{L}$ does not require any additional consumption since $x_{H}+d x_{H}-x_{L}=0$ and since $\widetilde{\delta}_{a}$ and the number of able people who work is unchanged. The number of able people who apply for and take up benefits is then also unchanged. Hence, from (3), $\widetilde{\delta}_{d}$ and the number of disabled taking up assistance does not change as well. Yet, all able workers now choose high-skilled jobs and earn $w_{H}\left(>w_{L}\right)$. Since the cost in terms of supplementary consumption is zero and the difference $w_{H}-w_{L}$ is strictly positive, a net receipt appears: $w_{H}-w_{L}>0$. The fiscal pie increases and more redistribution can occur. This will indubitably increase welfare. Therefore, it cannot be optimal for the government to let $x_{L}>x_{H}$ and, thus, consumption when producing more units must be larger: $x_{H} \geq x_{L}$.

\section{At the optimum, all detected able claimants go back to work: Proof}

Proof. Assume $\lim _{x \rightarrow 0} v(x)=-\infty$. Able agents choose either $v\left(x_{H}\right)-\delta_{a}$ or, with a probability $\mu$, $v\left(x^{u}\right)-\delta_{a}$ and with a probability $1-\mu, \operatorname{Max}\left\{v\left(x_{H}\right)-\delta_{a}, v(T)\right\}$, where $T$ is a welfare benefit. The ICC on able agents states

$$
v\left(x_{H}\right)-\widetilde{\delta}_{a}=\mu v\left(x^{u}\right)+(1-\mu)\left[\operatorname{Max}\left\{v\left(x_{H}\right)-\widetilde{\delta}_{a}, v(T)\right\}\right]
$$

Since $-\delta_{a}$ is not valued by the Paternalistic Utilitarian criterion and because efficiency matters, $\forall \delta_{a} \in[0, \infty)$, it is optimal that $v\left(x_{H}\right)-\delta_{a} \geq v(T)$. This is the famous "principle of maximum 
deterrence". Therefore, since $x_{H}>0$, the maximum penalty $T=0$ is optimal and all caught able people go back to work. Therefore, the ICC on able people can be written as (2).

Boadway and Cuff (1999) distinguish between the voluntarily and involuntarily non-employed. In their model, when the government perfectly identifies the voluntary unemployed, the maximum penalty of zero consumption is assumed. In this model, the maximum penalty to the voluntarily inactive able people implies that they do go back to work.

\section{Proof of Lemma 1}

Proof. (1) Both $\widetilde{\delta}_{a}$ and $\widetilde{\delta}_{d}$ are smaller than $\infty$. As $\forall \delta_{a}: g\left(\delta_{a}\right)>0\left(\forall \delta_{d}: f\left(\delta_{d}\right)>0\right)$, all able (disabled) people work means $\widetilde{\delta}_{a} \rightarrow \infty\left(\widetilde{\delta}_{d} \rightarrow \infty\right)$ at the optimum. Since consumption levels (and $\left.\sigma\left(\pi_{a}^{u}\right)\right)$ are finite, from $(2)$ and $((3)), \widetilde{\delta}_{a}$ and $\widetilde{\delta}_{d}$ cannot tend to $\infty$.

(2) If no one works, i.e., $\widetilde{\delta}_{a}=\widetilde{\delta}_{d}=0$, it is optimal for everyone to have the same consumption: $x_{l}=x_{h}=x_{b}=R^{\prime}$ with $R^{\prime} \stackrel{\text { def }}{\equiv} \operatorname{Max}\{0, R\}$. This allocation will not be optimal if those with the least $\delta$ were to choose to work for the additional consumption equal to their marginal product. It will be the case since $v\left(R^{\prime}+w_{Y}\right)>v\left(R^{\prime}\right) Y=L, H$. This implies that $\widetilde{\delta}_{d}>0\left(\widetilde{\delta}_{a}>0\right)$ at the optimum. More generally, for all planners with an objective function that is increasing in individual utilities, making some disabled work is optimal.

\section{E Proof and heuristic interpretation of Proposition 2}

This appendix derives the necessary conditions of Theorem (2) and gives heuristic interpretations. First-order condition with respect to $x_{L},(12)$

From the Lagrangian, the first-order condition with respect to $x_{L}$ gives

$$
\pi_{d}^{w}\left(\frac{v^{\prime}\left(x_{L}\right)}{\lambda}-1\right)=-\left(w_{L}-x_{L}+x_{b}+M(\mu)\right) \frac{\partial \pi_{d}^{w}}{\partial x_{L}} .
$$

Using (6) and (8), this necessary condition can be rewritten as (12).

A simple heuristic interpretation follows. Consider a small increase in consumption $x_{L}$ (e.g., a small reduction of the income tax in low-skilled jobs), around the optimal tax schedule. There are a mechanical effect and a behavioral (or labor supply response) effect.

Mechanical effect

There is a mechanical decrease in tax revenue equal to $-\pi_{d}^{w} d x_{L}$ because disabled workers have $d x_{L}$ additional consumption. This mechanically increases social welfare of disabled workers by their marginal social welfare weight $v^{\prime}\left(x_{L}\right) / \lambda\left(\equiv g_{L}\right)$. Thus, the mechanical welfare gain (expressed in terms of the value of public funds) as a result of $d x_{L}$ is equal to $\left(v^{\prime}\left(x_{L}\right) / \lambda\right) \pi_{d}^{w} d x_{L}$. Therefore, the total mechanical effect is $\pi_{d}^{w}\left(v^{\prime}\left(x_{L}\right) / \lambda-1\right) d x_{L}$.

Behavioral effect Behavioral responses imply a gain in tax revenue. The change $d x_{L}>0$ induces $\partial \pi_{d}^{w} / \partial x_{L}$ (pivotal) disabled workers to enter the labor force. Each worker leaving disability assistance induces a gain in government revenue equal to $w_{L}-x_{L}+x^{u}+M(\mu)$. That is the tax paid by each disabled worker $\left(w_{L}-x_{L}\right)$ and the savings from the benefits no longer paid to him/her as 
disabled recipient $\left(x^{u}\right)$, as well as the associated cost of monitoring $(M(\mu))$. The total behavioral gain is equal to $\left(w_{L}-x_{L}+x^{u}+M(\mu)\right)\left(\partial \pi_{d}^{w} / \partial x_{L}\right) d x_{L}$.

At the optimum, the sum of the mechanical and behavioral effects equals zero and gives (20).

First-order condition with respect to $x_{H},(13)$

Consider a small change $d x_{H}>0$. This change implies mechanical and behavioral effects on government revenue and welfare.

\section{Mechanical effect}

There is a mechanical decrease in tax revenue equal to $-\pi_{a}^{w} d x_{H}$ because able workers consume an additional $d x_{H}$. This mechanical decrease in tax revenue, however, is valued $\left(v^{\prime}\left(x_{H}\right) / \lambda-1\right) \pi_{a}^{w} d x_{H}$ by the government since each Euro not raised increases the consumption of able workers and this consumption gain is socially valued $v^{\prime}\left(x_{H}\right) / \lambda\left(\equiv g_{H}\right)$ in terms of public funds.

\section{Behavioral effect}

There are two effects (direct and indirect) on government revenue as a result of behavioral responses following $d x_{H}>0$.

(1) A direct behavioral response comes from $\partial \pi_{a}^{w} / \partial x_{H}$ (pivotal) previously inactive able agents who enter the labor force. Each recipient entering the labor force induces a gain in tax revenue of $w_{H}-x_{H}+x^{u}$, i.e., the tax paid by each new able worker $\left(w_{H}-x_{H}\right)$ and the benefit that stops being paid to him/her. There is also a gain in monitoring expenditures $M(\mu)$ for the $\left(\partial N_{a} G\left(\widetilde{\delta}_{a}\right) / \partial x_{H}\right)$ able people who stop applying for disability benefits. The gain in government expenditures is then $\left(w_{H}-x_{H}+x^{u}+M(\mu) / \mu\right)\left(\partial \pi_{a}^{w} / \partial x_{H}\right) d x_{H}$. The change $d x_{H}$ also induces a welfare gain since there are $\partial \pi_{a}^{w} / \partial x_{H}$ new pivotal workers whose aversion to work $\widetilde{\delta}_{a}$ is not valued in the welfare function. Valued in terms of public funds, this welfare gain is $\left(\widetilde{\delta}_{a} / \lambda\right)\left(\partial \pi_{a}^{w} / \partial x_{H}\right) d x_{H}$. (2) The previous direct behavioral effect implies an externality effect through the change in the take-up disutility: the change $d x_{H}$ indirectly induces $\partial \pi_{d}^{w} / \partial x_{H}$ pivotal disabled recipients to change their occupational choice as a result of stigma effects. Using the envelope theorem, (2) and (3), we have $\partial \pi_{d}^{w} / \partial x_{H}>0(<0)$ if $\partial \sigma / \partial \widetilde{\delta}_{a}>0(<0)$. Each disabled recipient entering the labor force induces a revenue gain of $w_{L}-x_{L}+x^{u}+M(\mu)$ for the government. Hence, the total gain is $\left(w_{L}-x_{L}+x^{u}+M(\mu)\right)\left(\partial \pi_{d}^{w} / \partial x_{H}\right) d x_{H}$. The change $d x_{H}$ also affects welfare through a change in the take-up cost's intensity of the $\pi_{d}^{u}$ disabled recipients. This change in terms of public funds is valued $-\pi_{d}^{u}\left(\partial \sigma / \partial x_{H} / \lambda\right) d x_{H}$ by the government. Then, all indirect effects implied by the stigma (or snowball take-up cost) externality when $d x_{H}>0$ are denoted by $\Omega\left(x_{H}, x_{L}, x^{u}, \mu\right)$, defined in Proposition 2.

At the optimum, the sum of the mechanical and all of the behavioral effects has to be nil, which gives:

$$
\begin{aligned}
& \pi_{a}^{w}\left(\frac{v^{\prime}\left(x_{H}\right)}{\lambda}-1\right)-\frac{\pi_{d}^{u}}{\lambda} \frac{\partial \sigma}{\partial x_{H}}+\frac{\widetilde{\delta}_{a}}{\lambda} \frac{\partial \pi_{a}^{w}}{\partial x_{H}}= \\
& -\left(w_{H}-x_{H}+x^{u}+\frac{M(\mu)}{\mu}\right) \frac{\partial \pi_{a}^{w}}{\partial x_{H}}-\left(w_{L}-x_{L}+x^{u}+M(\mu)\right) \frac{\partial \pi_{d}^{w}}{\partial x_{H}} .
\end{aligned}
$$

Using (7) and (9), the latter equation can be rewritten as (13). 
A necessary condition on the marginal cost of public funds $\lambda$, (14)

The necessary condition (14) comes from equations (12), (13), and the necessary condition with respect to $x^{u}$ that can be stated as

$$
\begin{aligned}
& \left(\pi_{a}^{u}+\pi_{d}^{u}\right)\left(\frac{v^{\prime}\left(x^{u}\right)}{\lambda}-1\right)-\frac{\pi_{d}^{u}}{\lambda} \frac{\partial \sigma}{\partial x^{u}}+\frac{\widetilde{\delta}_{a}}{\lambda} \frac{\partial \pi_{a}^{w}}{\partial x^{u}}= \\
& =-\left(w_{H}-x_{H}+x^{u}+\frac{M(\mu)}{\mu}\right) \frac{\partial \pi_{a}^{w}}{\partial x^{u}}-\left(w_{L}-x_{L}+x^{u}+M(\mu)\right) \frac{\partial \pi_{d}^{w}}{\partial x^{u}} .
\end{aligned}
$$

Dividing (20), (21), and (22) by $v^{\prime}\left(x_{L}\right), v^{\prime}\left(x_{H}\right)$, and $v^{\prime}\left(x^{u}\right)$, respectively, and adding these equations gives (14).

\section{First-order condition with respect to $\mu,(15)$}

$$
\begin{aligned}
& \frac{\partial £}{\partial \mu} \geq 0 \text { from }(15) \text { can be rewritten as: } \\
& \qquad \begin{array}{l}
\frac{\pi_{d}^{u}}{\lambda} \frac{\partial \sigma}{\partial \mu}+\frac{\pi_{a}^{w}}{\mu} \frac{\widetilde{\delta}_{a}}{\lambda} \leq \\
\frac{\partial \pi_{d}^{w}}{\partial \mu}\left(w_{L}-x_{L}+x^{u}+M(\mu)\right)-\frac{\pi_{a}^{u}}{\mu}\left(w_{H}-x_{H}+x^{u}\right)-\left(\pi_{d}^{u}+\frac{\pi_{a}^{u}}{\mu}\right) \frac{\partial M(\mu)}{\partial \mu} .
\end{array}
\end{aligned}
$$

We interpret this equation heuristically as follows. Consider $d \mu>0$, which implies the following mechanical and behavioral effects on government revenue and welfare:

\section{Mechanical effect}

There is a mechanical gain in monitoring expenditures equal to

$$
-\left(\pi_{d}^{u}+\pi_{a}^{u} / \mu\right)(\partial M(\mu) / \partial \mu) d \mu
$$

because the per capita cost on the $\left(\pi_{d}^{u}+\pi_{a}^{u} / \mu\right)$ people who are monitored is reduced $(\partial M(\mu) / \partial \mu<$ $0)$.

\section{Behavioral effect}

There are two effects on government revenue as a result of behavioral responses.

(1) There is a loss in tax revenue equal to $-\left(w_{H}-x_{H}+x^{u}\right) N_{a}\left(1-G\left(\widetilde{\delta}_{a}\right)\right) d \mu$ with $N_{a}\left(1-G\left(\widetilde{\delta}_{a}\right)\right) \equiv$ $\pi_{a}^{u} / \mu$, as a result of additional able people receiving disability benefits rather than working. This induces a welfare loss at the expense of workers whose disutility $\widetilde{\delta}_{a}$ was not valued in the paternalistic utilitarian criterion. That welfare loss expressed in public funds is $-\left(\widetilde{\delta}_{a} / \lambda\right)\left(\pi_{a}^{u} / \mu\right) d \mu$.

(2) Through stigma effects, $d \mu>0$ induces $\partial \pi_{d}^{w} / \partial \mu>0(<0)$ disabled agents to enter (leave) the labor force when $\partial \sigma / \partial \mu>0(\partial \sigma / \partial \mu<0)$. Each disabled recipient entering the labor force induces a gain in tax revenue of $w_{L}-x_{L}+x^{u}$, as well as a gain in monitoring cost of $M(\mu)$. In total, this indirect behavioral gain is $\left(w_{L}-x_{L}+x^{u}+M(\mu)\right)\left(\partial \pi_{d}^{w} / \partial \mu\right) d \mu$. The change $d \mu$ also affects welfare through a change in the stigma intensity of the $\pi_{d}^{u}$ disabled recipients. This change in terms of public funds is valued at $-\pi_{d}^{u}(\partial \sigma / \partial \mu / \lambda) d \mu$ by the government.

In case of an interior solution for $\mu$, all of these mechanical and behavioral effects sum to zero. The inequality (23) is then binding. 


\section{F $\quad$ Proof of Proposition 3}

Proof. From $\widetilde{\delta}_{d}>0$ and $\widetilde{\delta}_{a}>0$ (see Lemma 1) and (14), two rankings can prevail at the optimum, either:

$$
\begin{gathered}
\frac{1}{v^{\prime}\left(x_{H}\right)} \geqslant \frac{1}{v^{\prime}\left(x_{L}\right)}>\frac{1}{v^{\prime}\left(x^{u}\right)} \Leftrightarrow x_{H} \geqslant x_{L}>x^{u} \quad \text { or } \\
\frac{1}{v^{\prime}\left(x_{H}\right)}>\frac{1}{v^{\prime}\left(x^{u}\right)} \geqslant \frac{1}{v^{\prime}\left(x_{L}\right)} \Leftrightarrow x_{H}>x^{u} \geqslant x_{L}
\end{gathered}
$$

In both cases, (24) and (25), $v^{\prime}\left(x_{H}\right)<\lambda$. Moreover, if (24) prevails, we have: $v^{\prime}\left(x^{u}\right)>\lambda$ and if (25) is correct then: $v^{\prime}\left(x_{L}\right)>\lambda$. However, $v^{\prime}\left(x_{L}\right)>\lambda$ implies that the left-hand side of (12) is positive. This requires that $w_{L}-x_{L}+x^{u}+M(\mu)<0 \Leftrightarrow x_{L}-x^{u}>w_{L}+M(\mu)>0$, which contradicts $x^{u} \geqslant x_{L}$.

\section{G Proof of Proposition 4}

Proof. For contrast, we assume $\mu=0$. We then have $\sigma()=0,.{ }^{20} \pi_{a}^{w}=N_{a}$ (and the ICC on the able agents (2) is neglected). The first-order condition with respect to $x_{H}$ becomes:

$$
N_{a}\left(\frac{v^{\prime}\left(x_{H}\right)}{\lambda}-1\right)=0
$$

Therefore, $v^{\prime}\left(x_{H}\right)=\lambda$ when $\mu=0$. This implies that (14) (which is still valid with costless monitoring) becomes: ${ }^{21}$

$$
\frac{1-N_{a}}{v^{\prime}\left(x_{H}\right)}=\frac{\pi_{d}^{w}}{v^{\prime}\left(x_{L}\right)}+\frac{\pi_{d}^{u}}{v^{\prime}\left(x^{u}\right)}
$$

Since a weighted average with positive weights is bounded by its least and greatest elements, and since $x_{L}>x^{u}$ (from (3)): $\frac{1}{v^{\prime}\left(x_{L}\right)} \geq \frac{1}{v^{\prime}\left(x_{H}\right)} \geq \frac{1}{v^{\prime}\left(x^{u}\right)}$ with at least a strict inequality. From the first inequality: $x_{L} \geq x_{H}$. However $x_{L}>x_{H}$ does not prevail at the optimum (otherwise all able recognized as cheaters would work in low-skilled jobs, which is inefficient) hence $x_{L}=x_{H}$. Substitute the latter into (26) gives $v^{\prime}\left(x_{L}\right)=v^{\prime}\left(x^{u}\right)$ (since $\left.1-N_{a}=\pi_{d}^{w}+\pi_{d}^{u}\right)$. This contradicts $x_{L}>x^{u}$. Therefore $\mu>0$.

\footnotetext{
${ }^{20}$ With snowball take-up cost, $\mu=0$ implies that $\sigma\left(\pi_{a}^{u}\right)$ is maximal and is not affected by a marginal change in any consumption level. Therefore, this proof is still valid.

${ }^{21}$ Proof. When $\mu=0,(20)$ becomes

$$
\pi_{d}^{w}\left(\frac{v^{\prime}\left(x_{L}\right)}{\lambda}-1\right)=-\left(w_{L}-x_{L}+x^{u}\right) \frac{\partial \pi_{d}^{w}}{\partial x_{L}}=-\left(w_{L}-x_{L}+x^{u}\right) N_{d} f\left(\widetilde{\delta_{d}}\right) v^{\prime}\left(x_{L}\right)
$$

and (22) becomes:

$$
\pi_{d}^{u}\left(\frac{v^{\prime}\left(x^{u}\right)}{\lambda}-1\right)=-\left(w_{L}-x_{L}+x^{u}\right) \frac{\partial \pi_{d}^{w}}{\partial \widetilde{\delta_{d}}} \frac{\partial \widetilde{\delta_{d}}}{\partial x^{u}}=\left(w_{L}-x_{L}+x^{u}\right) N_{d} f\left(\widetilde{\delta_{d}}\right) v^{\prime}\left(x^{u}\right) .
$$

Dividing these two equations by $v^{\prime}\left(x_{L}\right)$ and $v^{\prime}\left(x^{u}\right)$, respectively, and adding them gives

$$
\frac{\pi_{d}^{w}+\pi_{d}^{u}}{\lambda}=\frac{\pi_{d}^{w}}{v^{\prime}\left(x_{L}\right)}+\frac{\pi_{d}^{u}}{v^{\prime}\left(x^{u}\right)}
$$

Substituting $\lambda=v^{\prime}\left(x_{H}\right)$ into the latter gives (26).
} 


\section{H Numerical method}

Combining constraints (2), (3), (5), and the paternalistic utilitarian criterion, it is convenient to rewrite the problem as:

$$
\begin{aligned}
& \widetilde{S}^{P}\left(\widetilde{\delta}_{d}, \widetilde{\delta}_{a}, \mu, x^{u}\right) \equiv N_{d}\left[\widetilde{\delta}_{d} F\left(\widetilde{\delta}_{d}\right)-\sigma\left(\widetilde{\delta}_{a}, \mu\right)-\int_{0}^{\widetilde{\delta}_{d}} \delta_{d} d F\left(\delta_{d}\right)\right]+ \\
& +\left[N_{a}\left((1-\mu)+G\left(\widetilde{\delta}_{a}\right)\right)\right] \widetilde{\delta}_{a}+v\left(x^{u}\right)
\end{aligned}
$$

with

$$
x^{u}\left(\widetilde{\delta}_{d}, \widetilde{\delta}_{a}, \mu\right)=\frac{\pi_{d}^{w} w_{L}+\pi_{a}^{w} w_{H}-\left(\pi_{d}^{u}+\frac{\pi_{a}^{u}}{\mu}\right) M(\mu)+R}{\pi_{d}^{w} e^{\widetilde{\delta}_{d}-\sigma\left(\widetilde{\delta}_{a}, \mu\right)}+\left(\pi_{d}^{u}+\pi_{a}^{u}\right)+\pi_{a}^{w} \widetilde{e}^{\widetilde{\sigma}_{a}}},
$$

where $u(.) \equiv \ln ($.$) and equations (2) and (3) have been used. Therefore, the problem becomes a$ three-dimensional problem $\left(\widetilde{\delta}_{d}, \widetilde{\delta}_{a}, \mu\right)$. Similarly, the constrained maximization of the utilitarian criterion can easily be rewritten as a three-dimensional problem.

The associated system of first-order conditions is highly nonlinear and too complex to be studied analytically. Therefore, since multiple local optima may exist, for each vector of parameters $\left(s, R, w_{L}, w_{H}, N_{d}\right)$ and for some specific distribution functions $F\left(\delta_{d}\right)$ and $G\left(\delta_{a}\right)$, and monitoring function $M(\mu)$, the objective function (27) is evaluated for an extremely wide range of values of the

endogenous variables $\left(\widetilde{\delta}_{d}, \widetilde{\delta}_{a}, \mu\right)$. Through this numerical method, we are able to check whether the solution found is the global optimum.

\section{References}

Aizer, A. and J. Currie (2004), Networks or Neighborhoods, Journal of Public Economics, 88(12): 25732585 .

Akerlof, G.A. (1978), The Economic of 'Tagging' as Applied to the Optimal Income Tax, Welfare Programs, and Manpower Training, American Economic Review, 68(2): 8-19.

Alesina, A. and G.-M. Angeletos (2005), Fairness and Redistribution: US Versus Europe, American Economic Review (Papers and Proceedings), 95: 913-935.

Arneson, R.J. (1990), Liberalism, Distributive Subjectivism, and Equal Opportunity for Welfare, Philosophy and Public Affairs, 19(2): 158-194.

Besley, T. and S. Coate (1992), Understanding welfare stigma: taxpayer resentment and statistical discrimination, Journal of Public Economics, 48(2): 165-183.

Benitez-Silva, H., Buchinsky, M., Chan H.M., Cheidvasser, S. and J. Rust (2004a) How large is the bias in self-reported disability? Journal of Applied Econometrics, 19: 649-670.

Benitez-Silva, H., Buchinsky, M. and J. Rust (2004b), How large are the classification errors in the social security disability award process?, NBER Working Paper, 10219.

Blundell, R. and T. MaCurdy (1999), Labor Supply: A Review of Alternative Approaches, in O. Ashenfelter and D. Cards, eds, Handbook of Labor Economics, Volume IIIA, Amsterdam: North-Holland.

Boadway, R., Marceau, N. and M. Sato (1999), Agency and the design of welfare systems, Journal of Public Economics, 73(1): 1-30.

Boadway, R. and K. Cuff (1999), Monitoring Job Search as an Instrument for Targeting Transfers, International Tax and Public Finance, 6(3): 317-37.

Bossert, W., Fleurbaey, M. and D. Van de Gaer (1999), Responsibility, talent and compensation: a secondbest analysis, Review of Economic Design, 4(1): 35-55. 
Campolieti, M. (2002), Moral Hazard and Disability Insurance: On the Incidence of Hard-to-Diagnose Medical Conditions in the Canada/Quebec Pension Plan Disability Program, Canadian Public Policy/Analyse de Politiques 28: 419-441.

Cremer, H., Lozachmeur, J-M. and P. Pestieau (2007), Disability Testing and Retirement, The Berkeley Electronic Journal of Economic Analysis and Policy, 7(1), art.10.

Cuff, K. (2000), Optimality of Workfare with Heterogeneous Preferences, Canadian Journal of Economics, $33(1): 149-174$.

Currie, J. (2006), The Take-Up of Social Benefits, in Poverty, The Distribution of Income, and Public Policy, Alan Auerbach, David Card, and John Quigley (eds), New York: Russell Sage: 80-149.

Diamond, P. (1980), Income Taxation with Fixed Hours of Work, Journal of Public Economics, 13(1): $101-110$

Diamond, P. and E. Sheshinski (1995), Economic aspects of optimal disability benefits, Journal of Public Economics, 57(1): 1-23.

Duflo, E. and E. Saez (2003), The Role of Information and Social Interactions in retirement Plan Decisions: Evidence from a Randomized Experiment, Quarterly Journal of Economics, 118(3): 815-842.

Eurostat (2001), Disability and social participation in Europe, Luxembourg: Office for Official Publications of the European Communities.

Goffman, E. (1963), Stigma: Notes on the management of spoiled identity, Trade Paperback Publisher: Prentice-Hall, Englewood Cliffs.

Harkness, J. (1993), Labour force participation by disabled males in Canada, Canadian Journal of Economics, 26(4), 878-889.

Hu, J., Lahiri, K., Vaughan, D.R. and B. Wixon (2001), A Structural Model of Social Security's Disability Determination Process, Review of Economics and Statistics, 83(2), 348-361.

Kanbur, R., J. Pirttilä and M. Tuomala (2006), Non welfarist optimal taxation and behavioral public economics, Journal of Economic Surveys, 20(5), 849-868.

Kleven, H.J. and W. Kopczuk (2010), Transfer Program Complexity and the take up of Social Benefits, Mimeo, January.

Kroft, K. (2008), Takeup, Social Multipliers and Optimal Social Insurance, Journal of Public Economics, 92(3-4): 722-737.

Lindbeck, A., Nyberg, S. and J.W. Weibull (1999), Social norms and economic incentives in the welfare state, Quarterly Journal of Economics, 114(1), 1-35.

Marchand, M., Pestieau, P. and M. Racionero (2003), Optimal redistribution when different workers are indistinguishable, Canadian Journal of Economics, 36(4), 911-922.

Meghir C. and D. Phillips (2008), Labour Supply and Taxes, IZA discussion paper 3405.

Mirrlees, J.A. (1971), An Exploration in the Theory of Optimum Income Taxation, Review of Economic Studies, 38(2), 175-208.

O'Donoghue, T. and M. Rabin (2003), Studying optimal paternalism, illustrated by a model of sin taxes, American Economic Review, 93(2), 186-191.

Parsons, D.O. (1996), Imperfect 'Tagging' in Social Insurance Programs, Journal of Public Economics, 62(1-2), 187-207.

Pestieau, P. and M. Racionero (2009), Optimal redistribution with unobservable disability: welfarist versus non-welfarist social objectives, European Economic Review, 53(6), 636-644.

Pudney, S., Hancock, R., and H. Sutherland, (2006), Simulating the reform of means-tested benefits with endogenous take-up and claim costs, Oxford Bulletin of Economics, 68(2), 135-166.

Roemer, J. (1998), Equality of Opportunity, Cambridge MA: Harvard University Press.

Saez, E. (2001), Using Elasticities to Derive Optimal Income Tax Rates, Review of Economic Studies, 68(1): 205-229.

Saez, E. (2002), Optimal Income Transfer Programs: Intensive versus Extensive Labor Supply Responses, Quarterly Journal of Economics, 117(3): 1039-1073.

Salanié, B. (2002), Optimal Demogrants with Imperfect Tagging, Economics Letters, 75(3), 319-324. 
Schokkaert, E., Van de gaer, D., Vandenbroucke, F. and R.I. Luttens (2004), Responsibility sensitive egalitarianism and optimal linear income taxation, Mathematical Social Sciences, 48(2): 151-182.

Sen, A.K. (1995), The political economy of targeting, in van De Walle, D. and Nead, K. (eds.), Public Spending and the Poor, Baltimore: J. Hopkins University Press, 11-24.

Social Security Administration (2006), SSI Disabled Recipients who work, SSA Publication, Office of Policy and of Research, Evaluation, and Statistics, 13-11829.

Stoddard, S., Jans, L., Ripple, J.M. and L. Kraus (1998), Chartbook on work and disability in the United States, U.S. Department of Education, National Institute on Disability and Rehabilitation Research, Washington, D.C.

Wolff, J. (2004), Disability Among Equals, in Philosophy and Disability, K. Brownlee and A. Cureton (eds), Oxford University Press. 


\section{CESifo Working Paper Series}

for full list see www.cesifo-group.org/wp

(address: Poschingerstr. 5, 81679 Munich, Germany, office@cesifo.de)

2953 Roland Strausz, The Political Economy of Regulatory Risk, February 2010

2954 Sanjay Jain, Sumon Majumdar and Sharun W. Mukand, Workers without Borders?

Culture, Migration and the Political Limits to Globalization, February 2010

2955 Andreas Irmen, Steady-State Growth and the Elasticity of Substitution, February 2010

2956 Bengt-Arne Wickström, The Optimal Babel - An Economic Framework for the Analysis of Dynamic Language Rights, February 2010

2957 Stefan Bauernschuster and Helmut Rainer, From Politics to the Family: How Sex-Role Attitudes Keep on Diverging in Reunified Germany, February 2010

2958 Patricia Funk and Christina Gathmann, How do Electoral Systems Affect Fiscal Policy? Evidence from State and Local Governments, 1890 to 2005, February 2010

2959 Betsey Stevenson, Beyond the Classroom: Using Title IX to Measure the Return to High School Sports, February 2010

2960 R. Quentin Grafton, Tom Kompas and Ngo Van Long, Biofuels Subsidies and the Green Paradox, February 2010

2961 Oliver Falck, Stephan Heblich, Alfred Lameli and Jens Suedekum, Dialects, Cultural Identity, and Economic Exchange, February 2010

2962 Bård Harstad, The Dynamics of Climate Agreements, February 2010

2963 Frederick van der Ploeg and Cees Withagen, Is There Really a Green Paradox?, February 2010

2964 Ingo Vogelsang, Incentive Regulation, Investments and Technological Change, February 2010

2965 Jan C. van Ours and Lenny Stoeldraijer, Age, Wage and Productivity, February 2010

2966 Michael Hoel, Climate Change and Carbon Tax Expectations, February 2010

2967 Tommaso Nannicini and Roberto Ricciuti, Autocratic Transitions and Growth, February 2010

2968 Sebastian Brauer and Frank Westermann, A Note on the Time Series Measure of Conservatism, February 2010

2969 Wolfram F. Richter, Efficient Education Policy - A Second-Order Elasticity Rule, February 2010 
2970 Tomer Blumkin, Yoram Margalioth and Efraim Sadka, Taxing Children: The Redistributive Role of Child Benefits - Revisited, February 2010

2971 Chang Woon Nam and Georg Wamser, Application of Regionally Varying Additionality Degrees in the Practice of EU Cohesion Policy, February 2010

2972 Ali Bayar, Frédéric Dramais, Cristina Mohora, Masudi Opese and Bram Smeets, Modeling Russia for Climate Change Issues, February 2010

2973 Magnus Söderberg, Informal Benchmarks as a Source of Regulatory Threat in Unregulated Utility Sectors, March 2010

2974 Piotr Wdowiński and Marta Malecka, Asymmetry in Volatility: A Comparison of Developed and Transition Stock Markets, March 2010

2975 Frans van Winden, Michal Krawczyk and Astrid Hopfensitz, Investment, Resolution of Risk, and the Role of Affect, March 2010

2976 Hyun-Ju Koh and Nadine Riedel, Do Governments Tax Agglomeration Rents?, March 2010

2977 Johann K. Brunner and Susanne Pech, Optimum Taxation of Bequests in a Model with Initial Wealth, March 2010

2978 Guglielmo Maria Caporale and Nicola Spagnolo, Stock Market Integration between three CEECs, Russia and the UK, March 2010

2979 Florian Englmaier, Ales Filipi and Ravi Singh, Incentives, Reputation and the Allocation of Authority, March 2010

2980 Konstantinos Angelopoulos, George Economides and Apostolis Philippopoulos, What is the Best Environmental Policy? Taxes, Permits and Rules under Economic and Environmental Uncertainty, March 2010

2981 Frederick van der Ploeg, Rapacious Resource Depletion, Excessive Investment and Insecure Property Rights, March 2010

2982 Wolfram F. Richter and Christoph Braun, Efficient Subsidization of Human Capital Accumulation with Overlapping Generations and Endogenous Growth, March 2010

2983 Francesco Cinnirella, Marc Piopiunik and Joachim Winter, Why Does Height Matter for Educational Attainment? Evidence from German Pre-Teen Children, March 2010

2984 Bernard Van Praag, Well-being Inequality and Reference Groups - An Agenda for New Research, March 2010

2985 Francesca Barion, Raffaele Miniaci, Paolo M. Panteghini and Maria Laura Parisi, Profit Shifting by Debt Financing in Europe, March 2010 
2986 Alexander Haupt and Magdalena Stadejek, The Choice of Environmental Policy Instruments: Energy Efficiency and Redistribution, March 2010

2987 John Komlos and Marek Brabec, The Trend of BMI Values among US Adults, March 2010

2988 Emanuele Massetti and Lea Nicita, The Optimal Climate Policy Portfolio when Knowledge Spills across Sectors, March 2010

2989 Helmut Rainer and Thomas Siedler, Family Location and Caregiving Patterns from an International Perspective, March 2010

2990 Toru Kikuchi and Ngo Van Long, A Simple Model of Service Offshoring with Time Zone Differences, March 2010

2991 Assaf Razin, Efraim Sadka and Benjarong Suwankiri, Migration and the Welfare State: Dynamic Political-Economy Theory, March 2010

2992 Bård Harstad, Buy Coal! Deposit Markets Prevent Carbon Leakage, March 2010

2993 Axel Dreher, Stephan Klasen, James Raymond Vreeland and Eric Werker, The Costs of Favoritism: Is Politically-driven Aid less Effective?, March 2010

2994 Sven Neelsen and Thomas Stratmann, Effects of Prenatal and Early Life Malnutrition: Evidence from the Greek Famine, March 2010

2995 Claude Hillinger and Bernd Süssmuth, The Quantity Theory of Money: An Assessment of its Real Linchpin Prediction, March 2010

2996 Matthew M. Chingos and Martin R. West, Do More Effective Teachers Earn More Outside of the Classroom?, March 2010

2997 Laurence Jacquet and Dirk Van de gaer, A Comparison of Optimal Tax Policies when Compensation or Responsibility Matter, March 2010

2998 Valentina Bosetti, Carlo Carraro, Romain Duval and Massimo Tavoni, What Should we Expect from Innovation? A Model-Based Assessment of the Environmental and Mitigation Cost Implications of Climate-Related R\&D, March 2010

2999 Scott Alan Carson, Nineteenth Century Stature and Family Size: Binding Constraint or Productive Labor Force?, March 2010

3000 Jukka Pirttilä and Ilpo Suoniemi, Public Provision, Commodity Demand and Hours of Work: An Empirical Analysis, March 2010

3001 Bertrand Candelon and Franz C. Palm, Banking and Debt Crises in Europe: The Dangerous Liaisons?, March 2010

3002 Joan Costa-i-Font and Marin Gemmill-Toyama, Does Cost Sharing really Reduce Inappropriate Prescriptions?, March 2010 
3003 Scott Barrett, Climate Treaties and Backstop Technologies, March 2010

3004 Hans Jarle Kind, Tore Nilssen and Lars Sørgard, Price Coordination in Two-Sided Markets: Competition in the TV Industry, March 2010

3005 Jay Pil Choi and Heiko Gerlach, Global Cartels, Leniency Programs and International Antitrust Cooperation, March 2010

3006 Aneta Hryckiewicz and Oskar Kowalewski, Why do Foreign Banks Withdraw from other Countries? A Panel Data Analysis, March 2010

3007 Eric A. Hanushek and Ludger Woessmann, Sample Selectivity and the Validity of International Student Achievement Tests in Economic Research, March 2010

3008 Dennis Novy, International Trade and Monopolistic Competition without CES: Estimating Translog Gravity, April 2010

3009 Yin-Wong Cheung, Guonan Ma and Robert N. McCauley, Renminbising China's Foreign Assets, April 2010

3010 Michel Beine and Sara Salomone, Migration and Networks: Does Education Matter more than Gender?, April 2010

3011 Friedrich Schneider, Tilman Brück and Daniel Meierrieks, The Economics of Terrorism and Counter-Terrorism: A Survey (Part I), April 2010

3012 Friedrich Schneider, Tilman Brück and Daniel Meierrieks, The Economics of Terrorism and Counter-Terrorism: A Survey (Part II), April 2010

3013 Frederick van der Ploeg and Steven Poelhekke, The Pungent Smell of "Red Herrings": Subsoil Assets, Rents, Volatility and the Resource Curse, April 2010

3014 Vjollca Sadiraj, Jan Tuinstra and Frans van Winden, Identification of Voters with Interest Groups Improves the Electoral Chances of the Challenger, April 2010

3015 Guglielmo Maria Caporale, Davide Ciferri and Alessandro Girardi, Time-Varying Spot and Futures Oil Price Dynamics, April 2010

3016 Scott Alan Carson, Racial Differences in Body-Mass Indices for Men Imprisoned in $19^{\text {th }}$ Century US Prisons: A Multinomial Approach, April 2010

3017 Alessandro Fedele, Paolo M. Panteghini and Sergio Vergalli, Optimal Investment and Financial Strategies under Tax Rate Uncertainty, April 2010

3018 Laurence Jacquet, Take it or Leave it: Take-up, Optimal Transfer Programs, and Monitoring, April 2010 